\title{
Esophageal Carcinogenesis
}

\author{
Naoki Watanabe1, Masahito Shimizu², Takahiro Kochi², Yohei Shirakami², \\ Takuji Tanaka ${ }^{1,3 *}$ \\ ${ }^{1}$ Department of Diagnostic Pathology (DDP) \& Research Center of Diagnostic Pathology (RC-DiP), Gifu \\ Municipal Hospital, Gifu, Japan \\ ${ }^{2}$ Department of Internal Medicine/Gastroenterology, Gifu University Graduate School of Medicine, Gifu, Japan \\ ${ }^{3}$ Department of Tumor Pathology, Gifu University Graduate School of Medicine, Gifu, Japan \\ Email: ${ }^{*}$ takutt@gmhosp.gifu.gifu.jp
}

Received 4 July 2014; revised 4 August 2014; accepted 24 August 2014

Copyright (C) 2014 by authors and Scientific Research Publishing Inc.

This work is licensed under the Creative Commons Attribution International License (CC BY).

http://creativecommons.org/licenses/by/4.0/

(c) (i) Open Access

\section{Abstract}

Esophageal cancer is the sixth leading cause of cancer death and remains one of the least survivable cancers. Esophageal cancers show wide variations in incidence in different population, suggesting that environmental or lifestyle risk factors could be controlled to reduce risk of these diseases. There are two major histopathologic types (squamous cell carcinoma and adenocarcinoma) of esophageal epithelial malignancy. Recently, the rate of adenocarcinoma is increasing in developed countries: in the United States, $50 \%$ or more is adenocarcinoma and, in about $70 \%$, the increase especially in a white male serves as adenocarcinoma. Esophageal adenocarcinoma develops in the lower esophagus. In contrast, in Japan, the increase in adenocarcinoma is not clear and most (90\%) of esophageal cancers are squamous cell carcinoma. Such squamous cell carcinoma occurs onto the middle part esophagus mostly, and $60 \%$ or more of the whole esophagus cancer also develops in the middle and upper parts. These differences also influence the treatment results. The scope of this article is to discuss carcinogenesis in the esophagus by giving an overview about its histopathological characteristics and molecular mechanisms.

\section{Keywords}

Esophageal Neoplasms, Preneoplastic Lesions, Squamous Cell Carcinoma, Adenocarcinoma, Risk Factor

\section{Introduction}

Approximately 482,300 new cases of esophageal cancer and 406,800 mortalities from this malignancy are re*Corresponding author. 
ported annually worldwide [1]. Worldwide, esophageal cancer is the sixth leading cause of cancer death [2] and remains one of the least survivable cancers [3]. Esophageal cancer is the sixth and eighteenth leading cause of death from cancer in Japanese men and women, respectively: numbers of patients with esophageal cancer were 17,004 men and 2990 women in 2007 [4]. Esophageal cancers show wide variations in incidence in different population, suggesting that environmental or lifestyle risk factors could be controlled to reduce risk of these diseases. The life time risk of this malignancy is $0.8 \%$ for men and $0.3 \%$ for women [5]. The risk increases with age.

Two major types, squamous cell carcinoma and adenocarcinoma, of histopathology of esophageal epithelial malignancy are known (Table 1), each having its own characteristic pattern of incidence and constellation of risk factors (Table 2). Most esophageal cancer frequently occurring in the world is squamous cell carcinoma, and the majority of this type of malignancy occurs in developing countries. Areas with extremely high mortality have long been noted in areas of North Central China, Central Asia and Southern Africa [6]. In general, in high-risk populations, the rates are similar in males and females, whereas in low-risk populations, the majority

\section{Table 1. Classification of esophageal neoplasms.}

\begin{tabular}{|c|c|c|}
\hline & Benign & Malignant \\
\hline \multirow[t]{9}{*}{ Epithelial } & Squamous cell papilloma & Squamous cell carcinoma \\
\hline & Adenoma & Basaloid carcinoma \\
\hline & & Spindle cell carcinoma \\
\hline & & Adenocarcinoma \\
\hline & & Adenosquamous carcinoma \\
\hline & & Mucoepidermoid carcinoma \\
\hline & & Adenoid cystic carcinoma \\
\hline & & $\begin{array}{c}\text { Endocrine tumors (carcinoid tumor, small cell carcinoma, and } \\
\text { endocrine cell carcinoma) }\end{array}$ \\
\hline & & Undiffrentiated carcinoma \\
\hline \multirow[t]{6}{*}{ Non-epithelial } & Leiomyoma & Leiomyosarcoma \\
\hline & Rhabdomyoma & Rhabdomyosarcoma \\
\hline & $\begin{array}{l}\text { Neurogenic tumor (Schwannoma, neurofibroma, } \\
\text { and granular cell tumor) }\end{array}$ & Gastrointestinal stromal tumor (GIST) \\
\hline & Hemangioma & Malignant lymphoma \\
\hline & Lymphangioma & Malignant melanoma \\
\hline & Lipoma & \\
\hline Mixed & & Carcinosarcoma \\
\hline
\end{tabular}

\section{Table 2. Factors and predisposing disorders associated with esophageal malignany.}

\begin{tabular}{|c|c|}
\hline Environmental (geographic aspects) & $\begin{array}{l}\text { Low level of soil molybdenum ; Soil salinity; Thermal; } \\
\text { Vulcanization-process in factory; Water pollution by petroleum products }\end{array}$ \\
\hline Dietary & $\begin{array}{l}\text { Aflatoxins; Asbestos; Bush tea; Fungi (Fusarium, Altemaria spp.); Malze consumption; } \\
\text { Nutritional deficiencies of vitamin A, E, and C; Niacin; Zinc }\end{array}$ \\
\hline Chronic irritation & Achalasia; Scleotherapy by injection; Reflux esophagitis (Barrett's esophagus); Lye ingestion \\
\hline Habit & Alcohol beverage; Smoking \\
\hline Cultural & Low socioeconomic status; Race \\
\hline Miscellaneous & $\begin{array}{l}\text { Hiatal herniation; Ionizing radiation; Papillomavirus infection; Pharyngoesophageal } \\
\text { diverticulum; Plummer-Vinson syndrome; Sprue; Tylosis }\end{array}$ \\
\hline
\end{tabular}


of cases occur in males. The risk is prominently related to use of alcoholic beverages and tobacco, and to both risk-enhancing and protective aspects of diet [7] among the proposed risk factors listed in Table 2. Particular attention has been given to nitrosamines [8] and to the putative interference with nitrosation by dietary antioxidants [9]-[11]. Carcinogens may be synthesized by microorganisms inhabiting poorly-preserved foods, which have been implicated in the etiology of esophageal cancer [12]. These include moldy grains and foodstuffs contaminated with the fungus Fusarium moniliforme, which produces fumonisin B a carcinogen, and is also capable of synthesizing nitrosamines from precursors.

Early stage esophageal cancer may be totally asymptomatic or may present with mild nonspecific symptoms such as heartburn, atypical chest pain, or dyspepsia. Patients may report mild or intermittent dysphagia, odynophagia (pain on swallowing food and liquids), or a foreign body sensation. These symptoms generally warrant diagnostic evaluation, including an esophagogastroduodenoscopy, including diagnostic mucosal biopsy. Some early cancers are diagnosed during routine upper endoscopic surveillance for Barrett's esophagus. The symptoms of esophageal cancer generally progress rapidly. Symptoms of advanced esophageal carcinoma become apparent with tumor growth. An initial inability to swallow solids is followed by difficulty in swallowing ground food and finally liquids. Progressive dysphagia is the most common complaint in most patients (about 90\%) with greater than $50 \%$ luminal occlusion or where luminal diameter is less than $13 \mathrm{~mm}$. Weight loss and anorexia are often present in patients with more advanced disease (due to inadequate intake of food secondary to dysphagia, or to a nonspecific effect of the cancer), predisposing the patient to nutritional deficits. Odynophagia occurs in about one half of the patients. Esophageal obstruction may cause aspiration of food and pneumonia. Tumor extension to the pericardium or mediastinum may cause retrosternal or back pain, as well as abscess formation. Hoarseness is usually associated with recurrent laryngeal nerve paralysis. Hiccups may occur due to mediastinal and/or diaphragmatic involvement of the tumor. Anemia and/or gastrointestinal bleeding and weakness may be present if the tumor is ulcerated and friable. Incessant cough and pneumonia should alert the clinician to the possibility of a tracheo- or bronchio-esophageal fistula resulting from tumor invasion of the nearby airways.

The incidence pattern of adenocarcinoma contrasts markedly with that for squamous cell carcinoma. The cancer tends to be much more common in developed countries, where it has increased dramatically over the past two decades and now accounts for the majority of new esophageal cases in many countries. In the United States, an increase of over 35\% was observed among white males between 1974 and 1994 [13]. Some of the highest incidence rates in the world are observed in Scotland and other parts of United Kingdom, with increasing incidence also reported in numerous other areas of western, but not Eastern Europe [14]. In the East, esophageal cancers are predominantly squamous cell in type, and mostly located in the middle third of the esophagus, as noted in Japan. There has not been a noticeable rise in the incidence of adenocarcinoma of the esophagus and gastric cardia. The exact cause of esophageal adenocarcinoma is uncertain, but is widely believed to be related to gastroesophageal reflux disease (GERD) and Barrett's esophagus (BE) [15]. Smoking and drinking wine and liquor are risk factors but less pronounced than for squamous cell carcinoma, and, in contrast to the latter, adenocarcinoma risk does not decrease with time after cessation of smoking or drinking [16].

Cancer of the esophagus is a potential participant in the "field cancerization" hypothesis of aerodigestive tract tumorigenesis [17]-[19]. In people with a long history of smoking, successfully removed cancers of the head and neck have a high risk of its recurrence and the second primary cancer, which can occur in the esophagus. As a primary tumor, cancer of the esophagus occurs relatively frequently throughout the world.

Understanding the pathogenesis and biologic nature of the specific precursor lesions that can be observed in the esophageal epithelium during neoplastic progression towards invasive cancers of two major histologic types of squamous cell origin and glandular origin is helpful to prevent and/or treat esophageal malignancies.

\section{Anatomy of Esophagus}

The esophagus is a hollow tube connecting the mouth and pharynx with the stomach. Its length varies with the height of the individual, ranging from 25 to $30 \mathrm{~cm}$. In the resting state, the esophagus is collapsed and measures about $3 \mathrm{~cm}$ in lateral diameter and $2 \mathrm{~cm}$ in anterior-posterior diameter. The esophagus begins at the level of the cricoid cartilage, at the apex of a funnel formed by the pharyngeal constrictors situated at the level of the 6th cervical vertebra. The International Union against Cancer (UICC) has subdivided the esophagus into four regions: a cervical region and three intrathoracic and abdominal regions: the incidence of esophageal cancer de- 
pends on the regions (Figure 1). The esophagus possesses no significant secretory or absorptive functions. Its only purpose is the transport of materials from the mouth to the stomach.

\section{Histology of Esophagus}

The esophageal wall consists of a mucosa, submucosa, tunica muscularis, and adventitia. The mucosa has three components: an outer stratified squamous epithelium; a thin muscle coat (the muscularis mucosa); and the lamina propria which is sandwiched in between the tow. In addition, esophageal cardiac glands similar to glands of the gastric cardia, consisting of mucous cells that secrete neutral mucin are commonly found in the lamina propria of the distal esophagus. The squamous epithelium is non-keratinized, although occasionally rare keratohyaline granules are present. It is composed three zones: the basal, prikle, and functional layers. The basal layer is thin, the prickle cell zone is composed of glycogen-rich flattened cells that occupy most of the epithelium, and the functional layer has a few flattened cells on the surface that are devoid of nuclei. $T$ cell lymphocytes are frequently scattered throughout the squamous epithelium and Langerhans' cells are occasionally present. The lamina propria consists of loose connective tissue containing mononulcear cells, lymphocytes, occasional plasma cells, and rare lymphoid follciles. In the distal esophagus, sparsely distributed mucous glands are present in the lamina propria between the musciaris mucosa and the overlying squamous epithelium. Mucosal or submucosal glands are not present in the rat esophagus. As in the rest of the gastrointestinal tract, the esophagus has an inner circular and an outer longitudinal muscle coat. The upper fourth of the esophagus contains entirely of striated muscle, the next quater contains a mixture of atriated and smooth muscle, and the lower half consists entirely of non-striated muscle. Unlike other gatsrointestinal tract, it is not surrounded by a serosa. This is important clinically since once a malignant neoplasm extends beyond the muscularis propria, it easily invades to the mediastinum.

\section{Esophageal Preneoplasia}

Dysplasia is an esophageal epithelial precancerous lesion. Histologically, it is characterized by nuclear enlargement and hyperchromaticity with increased mitotic activity. Dysplasia in the esophagus can either be squamous or glandular. Squamous cell dysplasia is found preceding or coexistent with squamous cell carcinoma. Glandular dysplasia is associated with adenocarcinoma complicating BE. Glandular dysplasia develops more frequently in the intestinal than in the gastric type of mucosa. Increasing grade of dysplasia, from mild to severe, is associated with an increasing risk of cancer. From a 3.5 year observation period, the cumulative incidence of squamous cell carcinoma was reported to be $30 \%$ for moderate dysplasia, and $65 \%$ for severe dysplasia or carcinoma in situ (CIS) [20]. High-grade dysplasia in BE may be associated with invasive cancer in one-third of patients. Progression from CIS to invasive carcinoma was estimated to take from 4 to 5 years in China, but studies from Japan suggested are within less than two years.

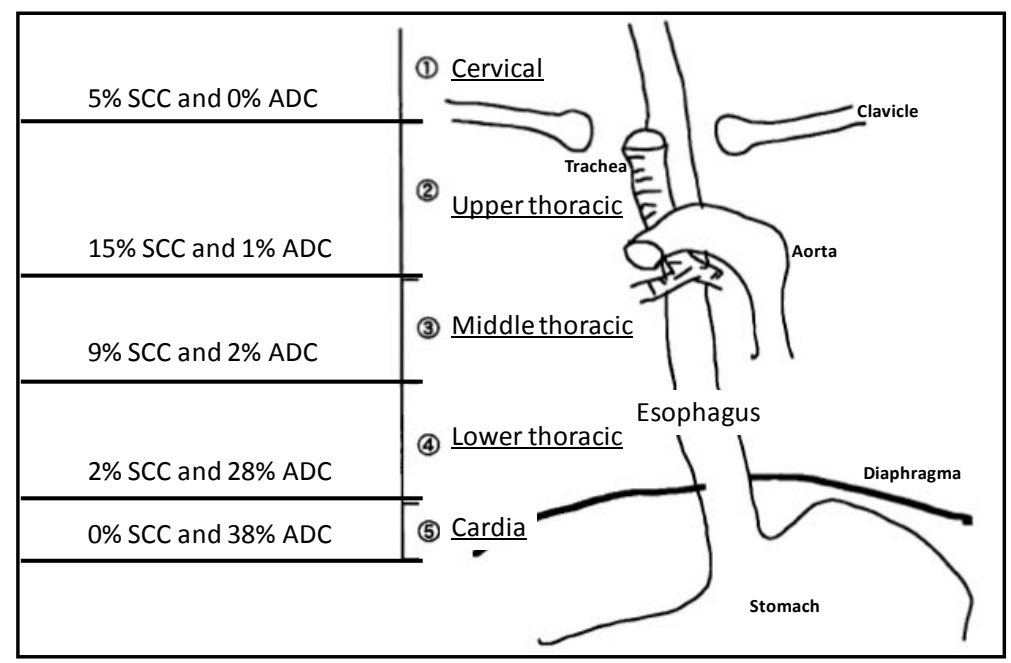

Figure 1. Incidence and location of the two types of esophageal malignancies. SCC, squamous cell carcinoma; and ADC, adenocarcinoma. 


\subsection{Squamous Cell Dysplasia}

Squamous cell dysplasia (Figure 2) is commonly found adjacent to invasive cancers, and follow-up studies of dysplasia have shown progression to cancer in many instances [21].

Dysplasia is defined morphologically by the presence of dysplastic cells which always include the basal layer and as in the cervix, extend throughout varying portions of thickness of the mucosa. When dysplastic cells affect only the basal layer up to about $1 / 3$ of the mucosa, it is designated mild; when it extends up to 2/3 it is moderate, and the upper third severe. When cancer cells but not dysplastic cells involve the full thickness of the mucosa, it is called CIS. However, many pathologists prefer not to use the term CIS and lump it with severe dysplasia. Esophagitis and mucosal atrophy have also been reported to be associated with esophageal cancer.

\subsection{Glandular Dysplasia in BE}

Searching of BE (Figure 3) aims to detect precursor lesions, namely glandular dysplasia for esophageal adeno-

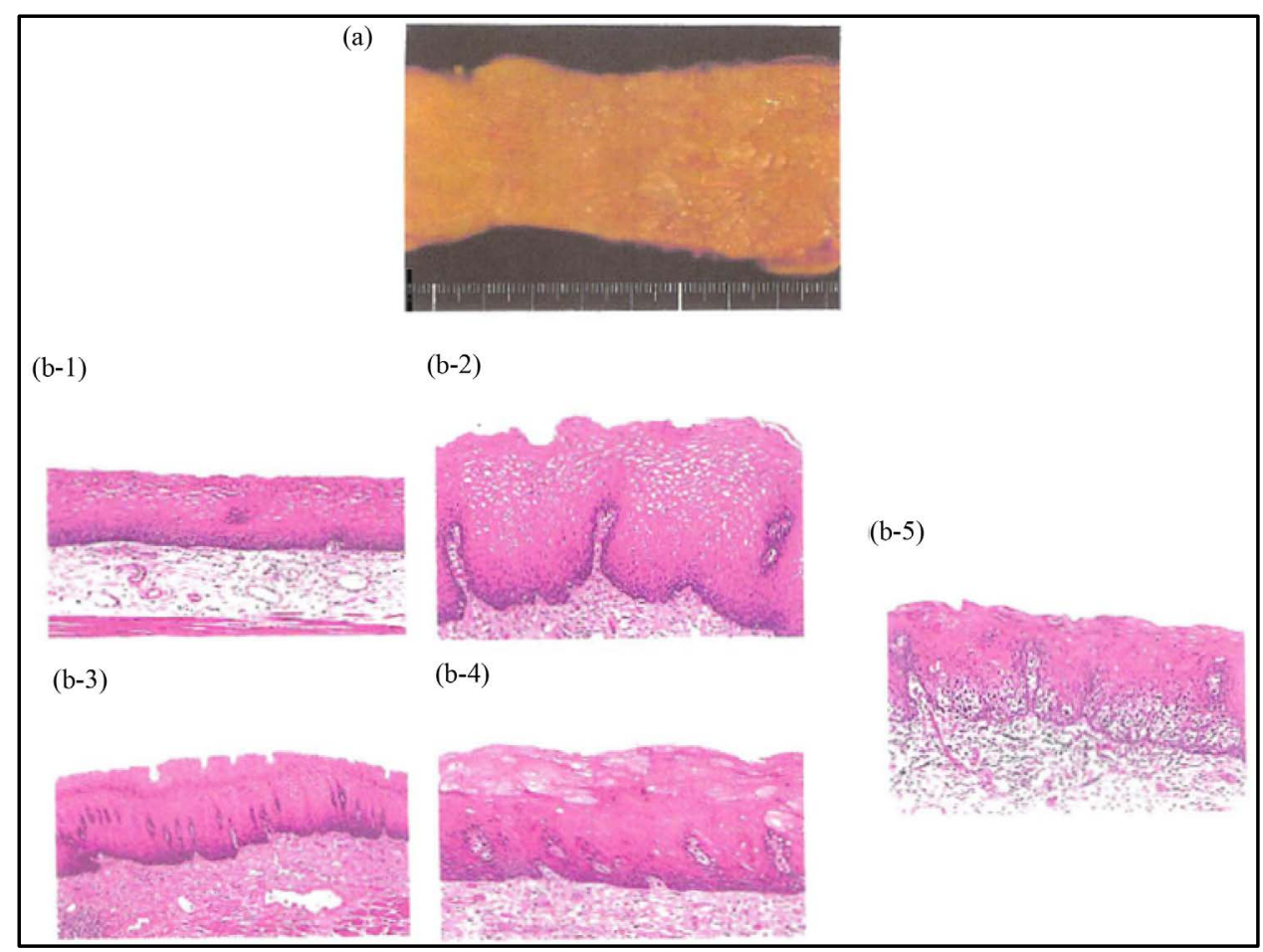

Figure 2. Macroscopic view (a) and histology (b) of human esophageal dysplasia. (b-1) Normal esophageal squamous epithelium; (b-2) Squamous cell hyperplasia with leukoplakia (glycogen acanthosis); (b-3) Mild dysplasia; (b-4) Moderate dysplasia; (b-5) Severe dysplasia.

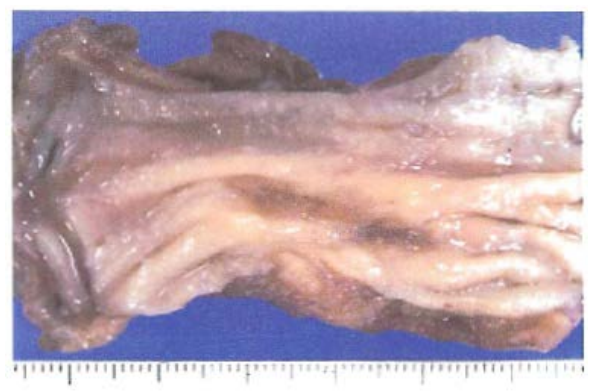

(a)

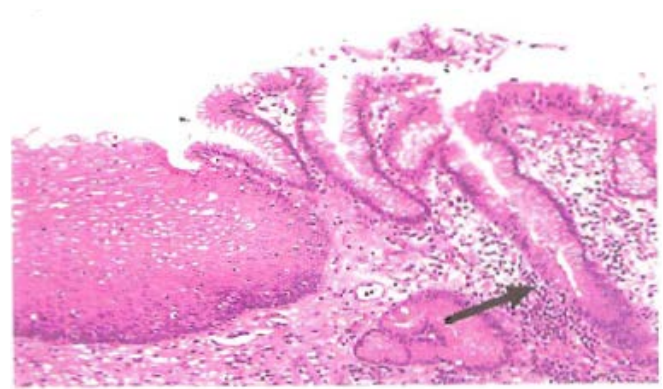

(b)

Figure 3. Macroscopic view (a) and histology of BE (b). Arrow in (b) shows mild dysplastic change. 
carcinoma, because of the recognized sequence of intestinal metaplasia to glandular dysplasia to invasive adenocarcinoma [22] [23]. The most recent WHO classification uses the terminology "intraepithelial neoplasia" instead of dysplasia. It is defined as unequivocal neoplastic change in the epithelium that is confined within the basement membrane [24]. In BE the dysplastic mucosa (Figure 4) develops both architectural and cytological changes. Dysplastic glands are commonly crowded with some variation in gland size. The epithelium lining the glands shows typical hyperchromatism, nuclear enlargement, nuclear crowding and loss of basal polarity similar to dysplasia at other sites. As in the colon and other sites, dysplasia is classified as indefinite for dysplasia, low-grade dysplasia and high-grade dysplasia. In low-grade dysplasia, the nuclei are cylindrical and located in the basal half of the cells. High-grade dysplasia generally shows more architectural atypia, including marked crowding with back-to-back and cribriform patterns and in some cases, dilated glands with irregular contours. The nuclei may be cylindrical with stratification that reaches the luminal surface of the epithelial cells, or they can be vesicular and more widely spaced. This latter form commonly has prominent nucleoli and shows loss of nuclear polarity, that is, the axis of the nucleus is not perpendicular to the basement membrane.

In most cases of glandular dysplasia, the cytological abnormalities extend onto the mucosal surface [24], a useful feature in the distinction from reactive atypia. However, in some cases, it remains uncertain whether epithelium exhibits reactive atypia or low-grade dysplasia ant, in this circumstance, a diagnosis of indefinite for dysplasia can be made. Significant inter- and intra-observer variation exists for the diagnosis of indefinite versus low-grade dysplasia; however, the diagnosis of high-grade dysplasia is generally more reliable, with good reproducibility of around $80 \%$. High-grade dysplasia can be difficult to distinguish from adenocarcinoma, even in esophagectomy specimens. Currently, the diagnosis of invasion can be made if there is: 1) Single cell invasion of lamina propria; 2) Stromal reaction to glands; and 3) Solid masses of neoplastic cells.

\section{Esophageal Neoplasms}

The WHO discriminates more than 20 histological subtypes of esophageal neoplasm (Table 1). However, adenocarcinoma and squamous cell carcinoma represent more than $90 \%$ of the malignant lesions detected.

\subsection{Squamous Cell Papilloma}

Benign tumors of the esophagus, including squamous cell papilloma with an estimated prevalence of 14/100,000 autopsies [25], are rare. As is the case of esophageal malignancies, there is a great difference in the geographical distribution of the esophageal squamous cell papilloma, with a high prevalence observed in the north-eastern part of Italy; approximately 75\% of all published cases are reported from Europe. The etiology and pathogenesis of squamous cell papilloma are controversial. It has been suggested that chemical, viral (HPV) or mechanical factors may contribute to the pathogenesis. For some authors, the most appealing etiology in humans is chronic irritation from reflux esophagitis.

Squamous cell papilloma of the esophagus generally appears as single round and elevated sessile formation, well delineated from surrounding tissue. Some of the reported cases have demonstrated multiple lesions. Men with esophageal papilloma outnumber women almost two to one; the reason for this is unclear. Papilloma is usually small in size (on average $0.6 \mathrm{~cm}$ ) and whitish or pinkish in color, with a soft consistency and a smooth or

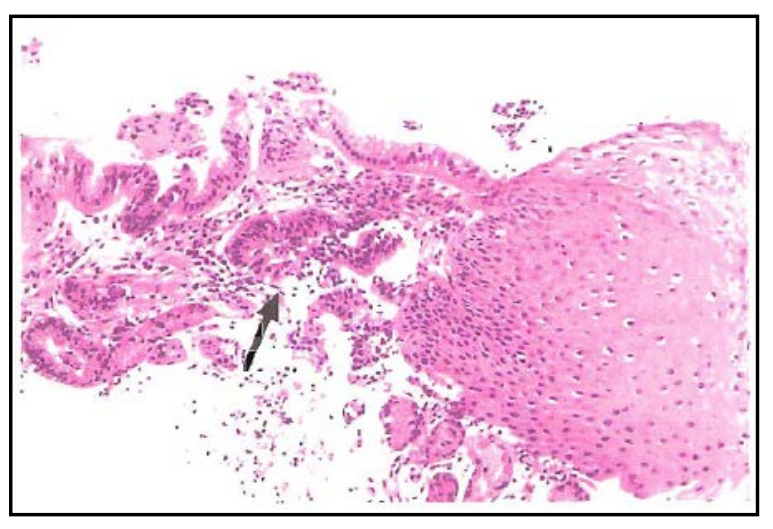

Figure 4. Histology of BE with dysplastic change (arrow). 
slightly rough surface. Morphologically, neoplastic squamous epithelium with slight nuclear atypia covers fibrovascular cores derived from the lamina propria. Squamous esophageal papilloma is a benign lesion, but there is much debate as to whether it is a premalignant lesion. At present, there is no evidence for this, and malignant changes have not been reported in humans.

\subsection{Squamous Cell Carcinoma}

Squamous cell carcinomas (Figure 5) originate from the stratified flat epithelium between the pharyngoesophageal junction and the GEJ, and represent the most common histological type (80\% - 90\%) among esophageal malignancies. Grossly, they can be classified into fungating (60\%), ulcerating (25\%), and infiltrating (15\%) tumors [26]. Fungating tumors project into the lumen from either a broad or narrow base and usually cause obstruction. Ulcerating tumors typically have a large ulcer, are less bulky, and may undermine the adjacent intact mucosa imparting a multi-nodular appearance. The tumor ulcer may penetrate into the mediastinum. These tumors often cause hemorrhage rather than obstruction. Circumferential involvement is common, causing thickening and rigidity of the esophageal wall and luminal stenosis [26]. Multiple esophageal squamous cell carcinomas are encountered in about $15 \%$ of patients [27]. Histologically, most of these tumors appear as well differentiated carcinomas with squamous pearl formation and individual cell keratinization (Figure 5). Poorly differentiated cancers may be composed of polyhedral cells often in a desmoplastic stroma, sometimes simulating a glandular-like epithelium. Glandular and adenoid cystic differentiation and sarcomatous features are sometimes encountered in esophageal cancer, and such histological variants often coexist with ordinary squamous cell carcinoma.

There are also a number of variants of squamous cell carcinoma such as verrucous carcinoma, spindle cell carcinoma, adenoid cystic carcinoma, mucoepidermoid carcinoma and small cell carcinoma (Table 1). Basaloid squamous cell carcinoma is a recently recognized, poorly differentiated variant of squamous cell carcinoma. Most tumors infiltrate through the muscularis propria into adjacent organs. The detection of neoplastic lesions as well as severe dysplasia is enhanced by the use of Lugol's iodine at endoscopy, both fail to stain, in contrast to normal mucosa, which stains strongly because of its high glycogen content. Submucosal extension of tumor may be marked and occurs primarily proximal to the tumor, particularly in the submucosal esophageal lymphatics.

Superficial esophageal cancer is an early form of invasive squamous cancer with involvement limited to the mucosa and submucosa and is the esophageal counterpart of early gastric cancer [28]. These tumors are rare in the US and have a much better prognosis than the usual squamous cancers, with $60 \%$ to $80 \%$ of patients surviving 5 years.

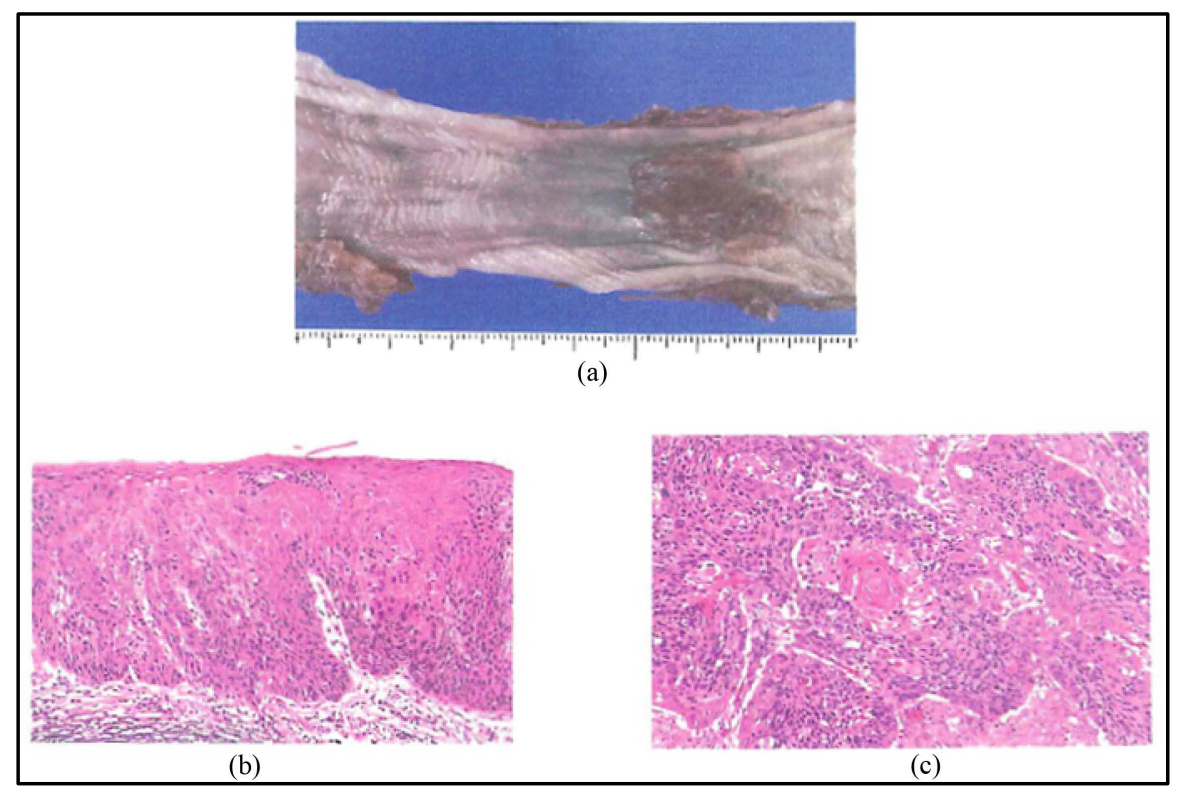

Figure 5. Human esophageal squamous cell carcinoma. (a) Macroscopic view; (b) Histology of carcinoma in situ; and (c) invasive squamous cell carcinoma. 


\subsection{Adenoma}

Adenomas of the esophagus are rare. In many of these reported, the term adenoma has referred simply to a benign glandular mass without implying the presence of dysplastic epithelium. The few esophageal adenomas (in the more restrictive, dysplastic sense) that have been identified have all occurred within metaplastic esophageal columnar epithelium, a condition known as BE [29]. Adenomas arising in BE are pedunculated polyp or nodular mass. Microscopically they consist of villo-tubular adenoma, tubular adenoma or villous adenoma. Dysplatic epithelium is present in adjacent non-polypoid or non-nodular Barrett's mucosa. Some are associated with adenocarcinoma. Occurrence of dysplasia and adenocarcinoma within esophageal adenomas, presence of adenomaous residues in cases of Barrett's adenocarcinoma, and possible association between malignant changes and increasing size of adenomas suggest that development of adenocarcinoma in BE may occasionally result from an adenoma-adenocarcinoma sequence like in the colon [30].

\subsection{Adenocarcinoma}

Primary adenocarcinoma (Figure 6) is the second most common histological type of esophageal cancers, accounting between $1 \%$ to $15 \%$ of all malignant esophageal tumors. Grossly, adenocarcinomas of the esophagus range from flat, infiltrative, and ulcerated lesions, to fungating polypoid masses. When the tumor has progressed beyond the early stages, the gross appearances vary from slight mucosal irregularities or plaques to obvious exophytic, fungating, or deeply ulcerated masses which may occlude varying proportions of the lumen. The red mucosa of BE may be present in the adjacent mucosa. Histologically, it is formed by glandular epithelium, with a papillary and/or tubular structure. Thus, adenocarcinomas arising in BE are usually well or moderately differentiate (Figure 6), but poorly differentiated and signet-ring cell carcinomas occur in about 20\% of cases [31]. Rare cases may show adeno-squamous differentiation. Most esophageal adenocarcinomas originate from areas of Barrett's epithelium or glandular metaplasia of the esophageal mucosa. Nearly $90 \%$ of adenocarcinomas have a site of predilection for the distal third of the esophagus. Other sites of origin of adenocarcinomas are islands of heterotopic gastric mucosa (the inlet patch) or cardiac glands and esophageal glands in the submucosa.

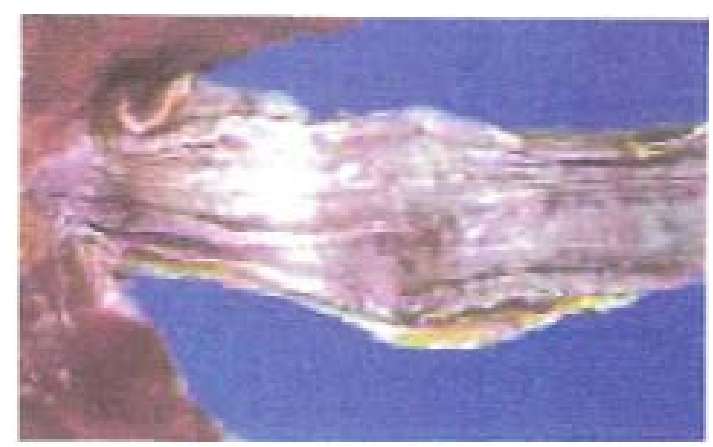

(a)

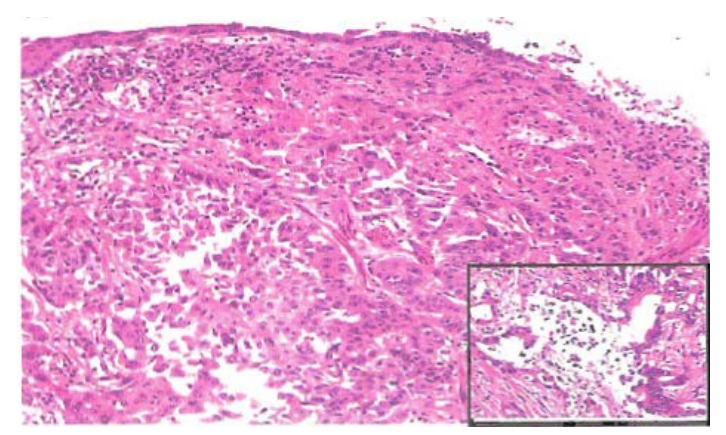

(b)

Figure 6. Human esophageal adenocarcinoma. (a) Macroscopic view and (b) Histology (Insert is part of welldifferentiated adenocarcinoma). 


\section{Risk Factors}

Smoking is associated with an increased risk of both squamous-cell carcinoma and adenocarcinoma of the esophagus (Table 2) [32] [33]. The ingestion of tobacco condensates is thought to bring tobacco carcinogens, particularly nitrosamines, in contact with the esophageal mucosa [34] [35]. The risk of esophageal cancer correlates directly with the quantity of cigarettes smoked per day and the duration of smoking [36]. Inflammation also contributes to the development of esophageal cancer [37] [38].

\subsection{Risk Factors for Esophageal Squamous Cell Carcinoma}

Any factor that causes chronic irritation and inflammation of the esophageal mucosa appears to increase the incidence of squamous-cell carcinoma of the esophagus. Substantial alcohol intake, especially in combination with smoking, greatly increases the risk of squamous-cell carcinoma, but not adenocarcinoma [39]. The combination of smoking and alcohol abuse is associated with a similarly increased risk of head and neck cancer; indeed, clinically unsuspected squamous cell carcinoma of the esophagus is discovered incidentally in approximately $1 \%$ to $2 \%$ of patients with head and neck cancers [40]-[42]. Other causes of chronic esophageal irritation include achalasia [43] and esophageal diverticulum [44], in which food is retained and decomposed by bacteria, releasing various chemical irritants. In several countries, frequent consumption of extremely hot beverages appears to increase the incidence of squamous-cell carcinoma [45].

\subsection{Risk Factors for Esophageal Adenocarcinoma}

Persons with recurring symptoms of reflux have an eightfold increase in the risk of esophageal adenocarcinoma [46]. Other markers of gastroesophageal reflux disease, such as hiatal hernia, esophageal ulcer, and frequent use of antacids or histamine-H2 blockers, are also associated with an increased risk but do not appear to be independent risk factors [47] [48]. Drugs that relax the gastroesophageal sphincter and increase reflux, such as anticholinergic agents, aminophyllines, and beta-blockers, may contribute to the development of up to $10 \%$ of these cancers [49]. It has been postulated that Helicobacter pylori infection (particularly strains positive for the CagA protein) may reduce the risk of severe gastroesophageal reflux disease [50] [51], thereby providing protection against the development of esophageal adenocarcinoma; this hypothesis remains unproven.

The increasing prevalence of obesity in the Western world is thought to add to the rising incidence of esophageal adenocarcinoma [52] [53]. It has been postulated that obesity increases intraabdominal pressure and gastroesophageal reflux, although one recent study provided contradictory results, and another found this hypothesis to be true only in women [54].

Barrett's esophagus develops in approximately $5 \%$ to $8 \%$ of patients with gastroesophageal reflux disease [55]. Barrett's esophagus may also occasionally occur in patients without symptoms of chronic reflux [56]. Mutations may develop within this metaplastic columnar epithelium, eventually transforming the columnar epithelium into areas of dysplasia. The dysplasia is characterized by a distortion of the glandular architecture, crowding of cell nuclei, and hyperchromatism. Patients with Barrett's esophagus are at high risk for esophageal adenocarcinoma, with an annual rate of neoplastic transformation of approximately $0.5 \%$ [48].

\section{Genetic Factors}

\subsection{Genetic Factors for Esophageal Squamous Cell Carcinoma}

Although familial clusters of esophageal cancer have been reported in several countries, nonepidermolytic palmoplantar keratoderma, a rare autosomal dominant disorder defined by a genetic abnormality at chromosome $17 q 25$, is the only recognized familial syndrome that predisposes patients to squamous-cell carcinoma of the esophagus [57].

\subsection{Genetic Factors for Esophageal Adenocarcinoma}

Familial Barrett's esophagus can be confirmed in 7.3\% of persons presenting with Barrett's esophagus, adenocarcinoma of the esophagus, or adenocarcinoma of the gastroesophageal junction [58]. The genetic and molecular changes underlying the development of Barrett's esophageal adenocarcinoma remain poorly understood. Genetic analysis of these cancers reveals frequent chromosomal losses (4q, 5q, 9p, and 18q), chromosomal gains 
(8q, 17q, and 20q), and occasional gene amplifications (7q, 8q, and 17q) [59]-[61]. Efforts to match specific chromosomal aberrations with particular genes have met with varying degrees of success. Genes (and their protein products) that may have a central role in the development of this cancer include cyclooxygenase 2, Bcl-2, $p 53$, $p 16, p 27$, cyclin $\mathrm{D} 1$, retinoblastoma protein, epidermal growth factor (and its receptor), erb-b2, E-cadherin-catenin, and -catenin [61]-[63].

\section{Diagnosis of Esophageal Cancer}

Diagnostic evaluation of the patient with esophageal carcinoma has two purposes: 1) to confirm the diagnosis through the use of radiography and/or endoscopy with biopsy and cytology; and 2) to determine the disease stage for initiation of appropriate therapeutic measures. Diagnostic methods for esophageal cancer included non-invasive diagnosis and endoscopic diagnosis. Staging is critical for the management of esophageal cancer. It stratifies treatment strategy into curative or palliative. It is also important for the evaluation of resectability in patients who are considered surgical candidates. Staging provides prognostic information, useful to physicians, patients, and families, to aid in management-related decisions in cases of advanced disease. Finally, staging can improve patient selection for neoadjuvant chemoradiation therapy.

\subsection{Non-Invasive Diagnosis}

Barium contrast radiography is one of the diagnostic tests for the evaluation of dysphagia and the associated symptoms of esophageal cancer. Though endoscopy is considerably more sensitive for detection of esophageal cancer, double-contrast barium esophagrams can detect early esophageal carcinomas. The diagnostic accuracy of the double-contrast barium esophagram is $70 \%$.

\subsection{Endoscopic Diagnosis}

Upper endoscopy involves the examination of the lining of the esophagus, stomach, and first part of the small intestine with a flexible endoscope. Gastrointestinal endoscopy allows the physician to visualize and biopsy the mucosa of the upper gastrointestinal tract. Endoscopy with biopsy is the primary method for diagnosing esophageal cancer. With this technique, biopsies may be directed, under endoscopic guidance, to abnormal areas for sampling and tissue diagnosis. Endoscopic brush cytology can also be helpful in obtaining a histological diagnosis, particularly in squamous cell carcinomas, which may yield indeterminate or non-diagnostic mucosal biopsies. Brush cytology is very useful in evaluating malignant-appearing strictures, particularly those that are non-traversable by the standard endoscope. The combination of endoscopic biopsy and brush cytology has the highest accuracy rate, close to $100 \%$, in obtaining a histological diagnosis of esophageal cancer.

Endoscopic ultrasonography (EUS) is a useful tool for the diagnosis of esophageal cancer. It is a highly technical, low-risk, diagnostic procedure that utilizes ultrasound to evaluate and diagnose digestive tract disorders. Endoscopic ultrasound allows imaging at close proximity and may detect subtle mucosal changes in the patient in whom other tests are nondiagnostic. High-frequency endoscopic ultrasonography may be helpful in directing endoscopic biopsy toward areas of endosonographic abnormalities in patients with Barrett's esophagus and high-grade dysplasia.

\section{Treatment of Esophageal Cancer}

Tumor stage generally determines the goal of treatment-to cure, prolong survival, or palliate cancer-related symptoms. Selection of therapy is contingent upon the medical condition of the patient, patient preferences, and available professional expertise. Unfortunately, because most esophageal cancers present in a late stage (tumors involving the submucosa tend to disseminate), the overall cure rate is low. Curative intent is usually reserved for localized tumors, Stage 0, I, or IIA (Tis, T1, T2, T3 with no regional lymph node metastasis).

\subsection{Therapy for Localized Cancer}

Several treatment options exist for localized esophageal cancer (any T stage, without regional lymphadenectomy). Traditionally, surgery is the treatment of choice in patients with early disease. However, endoscopic therapy has been shown to be a safe and effective alternative in patients with T1 cancer and multiple medical comor- 
bidities [64]-[67]. Chemoradiation therapy is also a suitable alternative in this high-risk group for whom surgery is not the best option. Radiation is another approach to a curative treatment for localized disease. Other treatment for localized esophageal cancer include radiation plus chemotherapy, chemotherapy plus surgery, chemoradiation plus surgery, endoscopic therapy for localized disease, endoscopic mucosal resection, and photodynamic therapy.

\subsection{Therapy for Advanced Esophageal Cancer}

Multimodality therapy offers the best chance for prolonged disease-free survival in advanced esophageal cancer (Stage IIB and III). However, the morbidity is significant and the cure rate is low. Multimodal therapy followed by surgery offers the chance of complete response and improved survival in about $30 \%-40 \%$ of patients. In nonsurgical candidates, radiation and chemotherapy alone may be an option. Palliative therapy can be offered to those patients in whom these therapeutic approaches are not an option or those patients with Stage IV or distant metastatic disease. Palliative esophagogastrectomy has been performed for severe obstruction but is associated with high morbidity and mortality. The goal of palliation is the relief of symptoms and improvement of quality of life. The aim of palliative therapy is to maintain comfort, avoid inpatient hospital care, and minimize treatment-related side effects. Other therapy methods for advanced esophageal cancer include chemoradiation therapy for palliation, and endoscopic therapy for palliation.

\section{Animal Models of Esophageal Carcinoma}

\subsection{Animal Models of Esophageal Squamous Cell Carcinoma}

Early efforts were made to induce the esophageal tumors of squamous cell origin in the rat, since it was known as early as the 1930s that epidermal tumors were readily induced by chemically carcinogens [68]. In the last two decades, however, the chemical synthesis of several alkylnitrosamines led to the discovery of organotropism for the esophagus when tested in rodents [69]-[71]. Among the most potent of the substituted nitrosamines is the compound $N$-nitrosomethylbenzylamine (NMBA). Many nitroso compounds are esophageal carcinogens in animal models and induce a high incidence of squamous cell tumors and preneoplasia (Figure 7), independent of

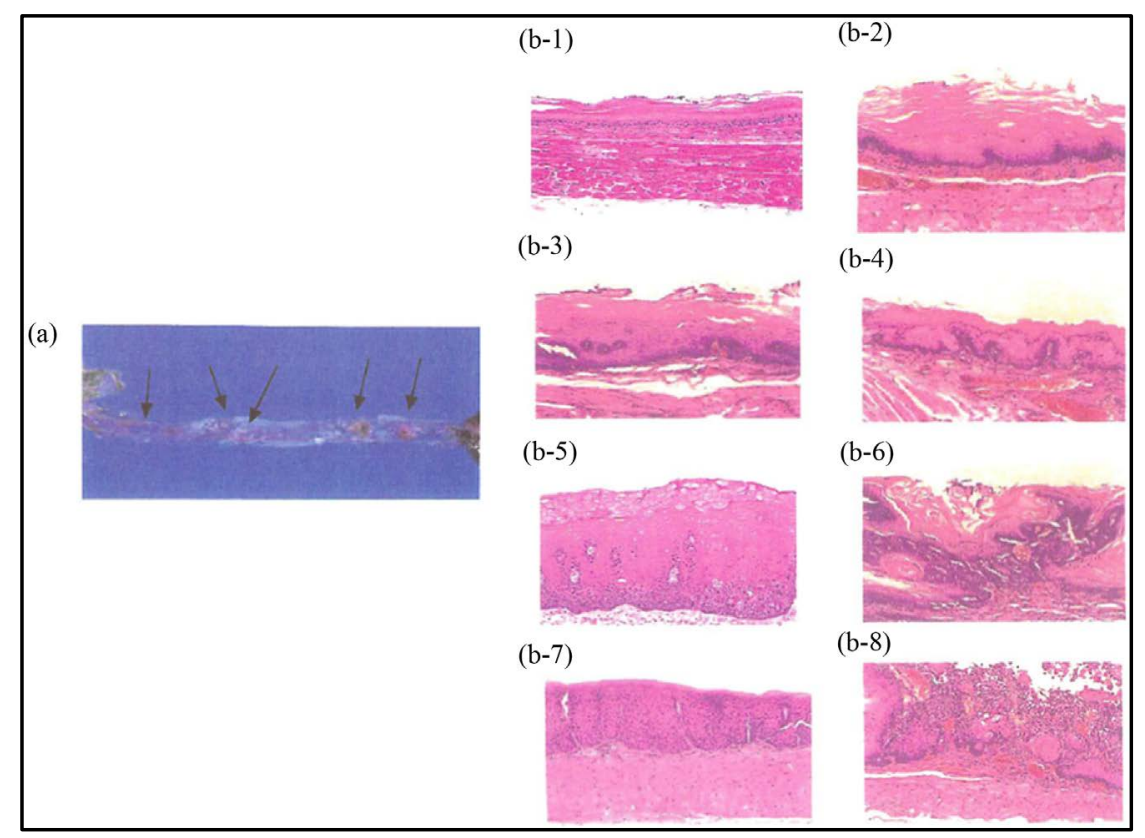

Figure 7. Various pathological lesions induced by NMBA in a rat esophagus: (a) Macroscopic view (arrows are tumors) and (b) Histology. (b-1) Normal esophageal squamous epithelium; (b-2) Squamous cell hyperplasia; (b-3) Mild dysplasia; (b-4) moderate dysplasia; (b-5) Severe dysplasia; (b-6) Squamous cell papilloma; (b-7) Squamous cell carcinoma in situ; and (b-8) invasive squamous cell carcinoma. 
the route of administration [69]. This observation confirms their potential role in etiology of human esophageal cancer. NMBA is the most potent esophageal carcinogen in the rat [69]. This carcinogen is notable amongst the nitrosamines, a chemical group containing some of the most potent of experimental carcinogens known to man. Due to an aromatic side chain, NMBA is much more lipid-soluble than water-soluble. Early attempts at testing NMBA for carcinogenicity revealed it to be highly specific for the esophagus in mice and rats [70]. The degree of carcinogenesis is dependent on the duration of NMBA treatment [72]. Lesions induced by NMBA (Figure 7) in the rat esophagus are histologically similar to human cancers of squamous cell origin. Carcinogenesis in the rat esophagus develops through several intermediate stages. Parenteral injections of NMBA induce severe esophagitis in the acute stages. From this origin, hyperplastic lesions progress through a papillary stage to squamous cell carcinoma [73]. Like many alkylating carcinogens, NMBA is a powerful methylating agent, and the 06 position of guanine in DNA is a prime target for mutagenesis [74]. NMBA-induced rat tumors also show a prevalence for mutations in the ras gene, in keeping with many experimentally induced tumors [75]. Much is known about the mechanism of action of NMBA carcinogenesis; the metabolism of this carcinogen has been well characterized [76] [77]. Although the final transformation of NMBA may occur in esophageal mucosal cells, it is first metabolized in the liver by cytochrome P-4502E1. This P-450 isozyme catalyzes the oxidation of a number of xenobiotics, including alcohol [78]. Human and rat esophageal cells or microsomes metabolically activate NMBA and several other esophageal nitrosamine carcinogens, including the tobacco smoke constituent N-nitrosonornicotine (NNN) and N-nitrosomethyl-n-amylamine (NMNA) [79] [80]. Since alcohol drinking has been epidemiologically linked to increased risk for esophageal cancer, the NMBA model has been used to explore possible mechanisms of carcinogenesis [81]. Most nitrosamine-induced esophageal carcinomas in rats, unlike the human malignancies, contain a H-ras mutation in codon 12 [82]. Nevertheless about $30 \%$ of the rat carcinomas present a p53 mutation, in the range of the 55\% seen in human esophageal cancers [82] [83]. In this context, a new animal model for esophageal squamous cell carcinoma developed by Tsuda's group is of interet [84]. In this model, multiple esophageal tumors, squamous cell carcinomas and papillomas, rapidly developed within 10 weeks in male H-ras 128 rats subcutaneously injected with NMBA $(0.5 \mathrm{mg} / \mathrm{kg}$ body weight, 3 times a week for 5 weeks) and then maintained for 5 weeks without any further treatment, while wild type rats had only a small numbers of mostly benign tumors.

A multitude of these animal models are exploited to increase our insight into tumor development in humans, to assess risk factors in the human environment, and to evaluate anticarcinogenic substances [10] [11] [81] [85].

\subsection{Animal Models of Esophageal Adenocarcinoma}

Much work has been done in the last decade in establishing esophageal adenocarcinoma models using N-nitrosamine augmentation or by iatrogenic GERD. In some of these models Barrett's columnar epithelium and dysplasia are present. These models have been used to examine the role of organic and non-organic materials and tumor-suppressor genes and the nature of GERD in the pathogenesis of Barrett's-associated adenocarcinoma. In experimental animal models, reflux of unacidified duodenal juice causes BE and esophageal adenocarcinoma, and excessive use of acid blockers might contribute to esophageal adenocarcinoma induction [86]. Miwa et al. [87] found that refluxed duodenal contents per se are responsible for esophageal carcinogenesis using their model without any exogenous carcinogen. Others also support a role for reflux of duodenal contents, including bile and pancreatic juice, rather than of gastric contents in the etiology of human esophageal adenocarcinoma [88].

Fein et al. [89] studied the role of GERD and development of adenocarcinoma without the use of carcinogens in the rats, and concluded that duodenoesophageal reflux is carcinogenic in the rat model and exogenous carcinogen is not necessary for cancer development in gastrectomized rats. They also studied the functional role of Apc and Trp53 tumor-suppressor genes in the development of esophageal adenocarcinoma in wild-type, p53knockout, or Apc-mutated mice and concluded that loss of either TrpS3 or Apc leads to the development of columnar metaplasia in 33\% and 25\% of mice, respectively, whereas loss of TrpS3, but not Apc, leads to development of cancer in mice with jejunoesophageal reflux [90].

Recent interesting studies by Chen et al. [91] [92] have also shown that direct anastomosis of squamous epithelium to columnar epithelium and mixed reflux of gastric and duodenal contents leads to the formation of columnar-lined esophagus, columnar-lined esophagus with dysplasia, and esophageal adenocarcinoma. In their study, the incidences of columnar-lined esophagus, those with dysplasia, and esophageal adenocarcinoma were 
53.5\%, 34.9\%, and 25.6\%, respectively, 40 weeks after surgery (esophagoduodenal anastomosis, Figure 8). In addition, esophagoduodenal anastomosis (Figure 8) could induce esophageal adenocarcinoma with a low incidence. Histology of these neoplasms was well-differentiated adenocarcinoma (Figure 9). Such esophageal carcinogenesis caused by surgical procedures can be potentiated by a carcinogen NMNA, a semipurified high-fat diet, diethylnitrosamine (DEN) [93], or iron overnutrition [92]. Thus, It appears that gastroduodenoesophageal reflux (GDER) is significantly more deleterious to esophageal mucosa than GER, and GDER in isolation is an esophageal carcinogen, causing BE and esophageal adenocarcinoma [93]. This Barrett's epithelium is similar to human BE with specialized types of goblet cells (containing sialomucin or sulfomucin) and columnar cells (containing acid or neutral mucin), as well as an incompletely developed brush border. Their results are consistent with the proposed human sequence for pathogenic events in BE progression to "BE with dysplasia" and then to esophageal adenocarcinoma [94]. The mechanism by which duodenal content reflux stimulates esophageal carcinogenesis in experimental animals could involve biliopancreatic and pancreatic reflux as both of these refluxes induce severe esophagitis and increased esophageal cell proliferation. This may be the mechanism by which BE develops and progresses to adenocarcinoma [95] [96].

Studies using mice also show that duodenogastroesophageal reflux induced by the carcinogen NMBA results in BE, Barrett's associated adenocarcinoma, or both in $57.1 \%$ of animals, consistent with findings in the rat model [97].

\section{Molecular Carcinogenesis}

Although various oncogenes, oncogene products, and suppressor genes have been identified in human esopha-
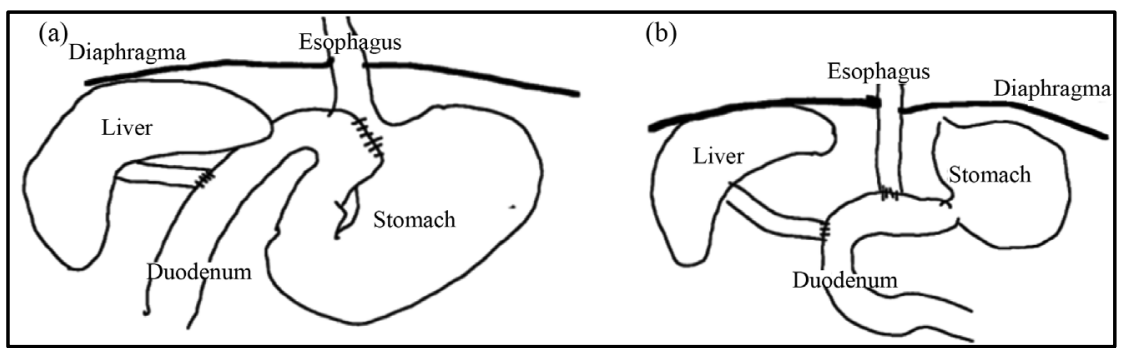

Figure 8. Surgical anastomoses for induction of BE and esophageal adenocarcinoma. (a) Esophagogastroduodenal anastomosis and (b) Esophagoduodenal anastomosis.

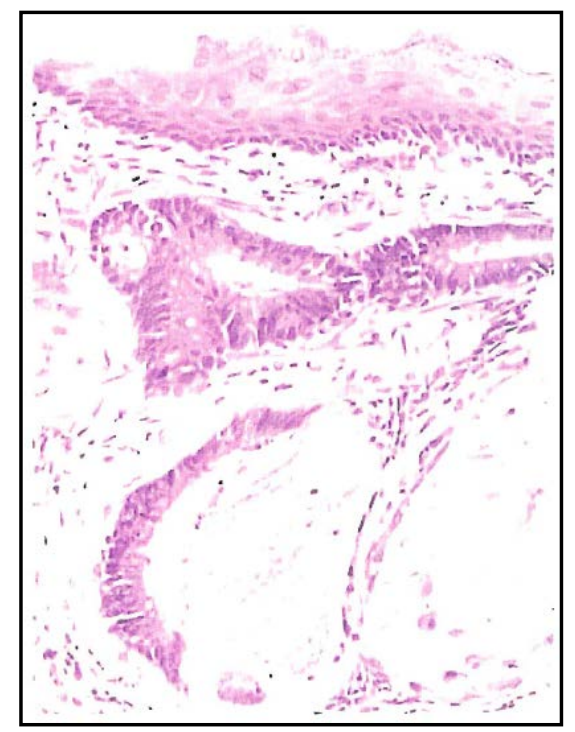

Figure 9. Histology of well-differentiated adenocarcinoma of the esophagus in a rat received esophagogastroduodenal anastomosis (Courtesy of Doctors Xianoxin Chen and Chung S. Yang, The State University of New Jersey, NJ, USA). 
geal carcinoma, their relation to disease development and outcome is only partly understood.

\subsection{Genetic Alterations in Esophageal Squamous Cell Carcinoma}

The most common genetic alterations found in esophageal cancer include allelic losses at chromosomes 3p, 5q, 9p, 9q, 13q, 17p, 17q, and 18q, as well as mutations of the tumor-suppressor gene $p 53$ (mostly mis-sense) and $R b$ (deletions), cyclin- $D 1$ gene (amplifications), and c-myc (amplifications). Mutations of $p 53$ differ in adenocarcinoma from squamous cell carcinoma by type, frequency, and distribution along the gene, and the p53 protein structure is altered differently [98]. The occurrence of genetic alterations associated with the development of squamous cell carcinoma and Barrett's adenocarcinoma of the esophagus is summarized in Figure 10.

\subsection{Molecular Pathogenesis of Barrett's Adenocarcinoma}

The molecular mechanisms involved in the development of Barrett's metaplasia and its progression to dysplasia and adenocarcinoma include allelic losses involving chromosome 17p and mutations in the p53 tumor-suppressor gene. In a prospective international study on p53 mutations, 48 patients with BE and 50 patients with Barrett's cancer were evaluated. Exons 5 through 9 of the p53 gene were studied for the presence of mutations by single-strand conformational polymorphism analysis after polymerase chain reaction (PCR) amplification. No p53 mutations were seen in any of the tissue samples from patients with BE alone and no dysplasia or low-grade dysplasia. Of the patients with Barrett's cancer, however, 23 (46\%) had p53 mutations in Barrett's epithelium, tumors, or both. The fact that mutations could be detected in premalignant Barrett's epithelium may be a marker for the development of invasive cancer [99]. The best predictor of progression of Barrett's epithelium to cancer is high-grade dysplasia. Aneuploidy and an abnormal chromosome complement are seen in squamous cell carcinoma and squamous dysplasia, as well as in all stages of Barrett's-associated carcinogenesis.

\section{Conclusions}

The high incidence rate and poor survival from esophageal cancer provide a compelling rationale for identifying precursor lesions that distinguish individuals at high risk of developing invasive esophageal carcinoma. Such biomarkers are potentially useful in two major ways. First, they can be employed as intermediate outcomes

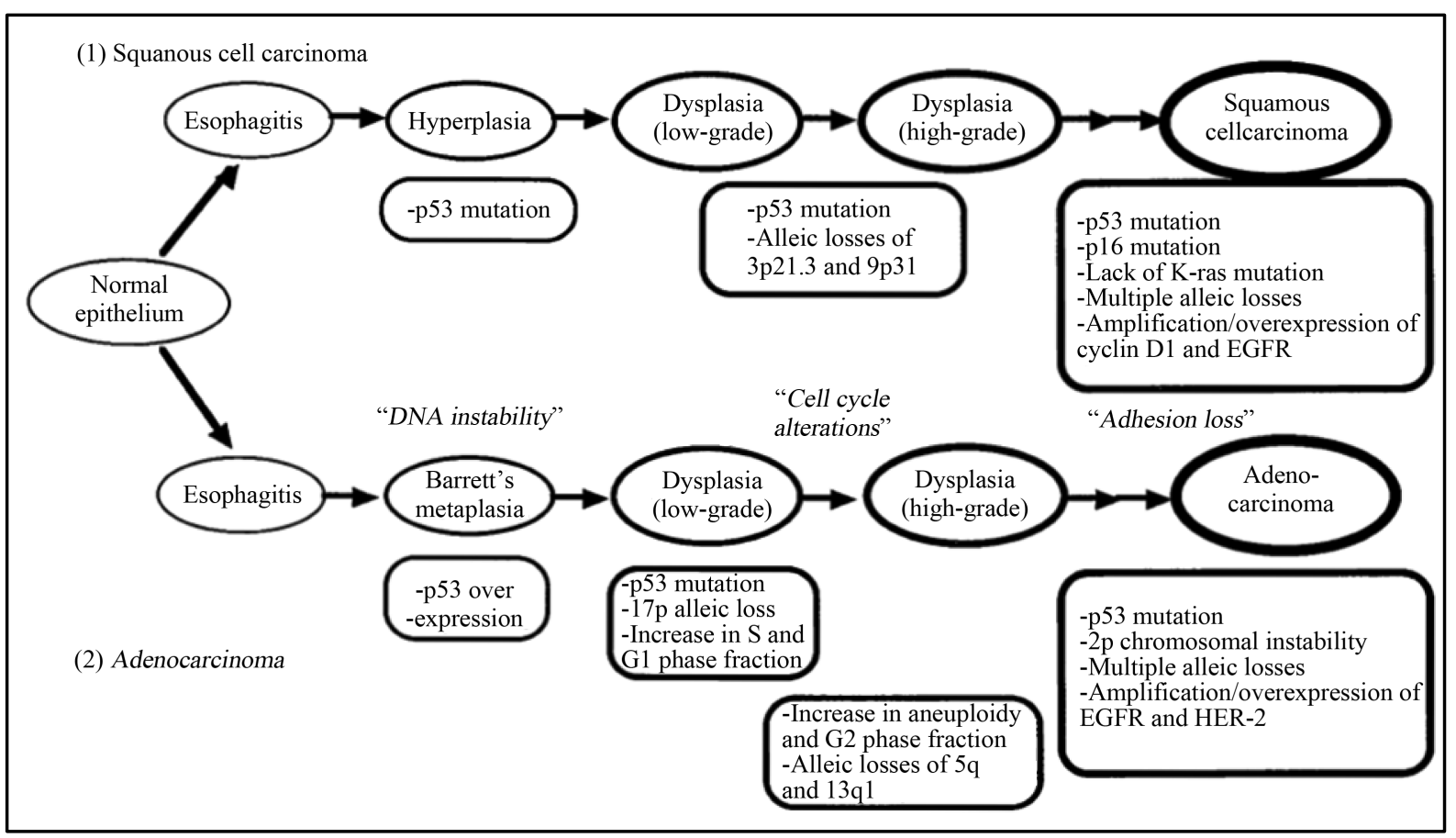

Figure 10. Histological and genetic alterations in esophageal cancer. 
for observational studies and prevention trials. Using an intermediate endpoint, as opposed to a cancer endpoint, can substantially reduce the number of participants and the length of follow-up needed to test hypotheses. It can also allow the determination of the stage(s) at which specific risk factors act, which can shed light on mechanisms of action and help identify specific interventions that are most effective for a particular precancerous disease state. Second, they can identify persons who would be most likely to benefit from cancer prevention activities. These might include modification of exposure to risk or preventive factors, medical or surgical interventions aimed at eliminating precancerous lesions before they progress to cancer, and surveillance programs designed to identify cancerous or near-cancerous lesions at an early, treatable stage.

Environmental factors, particularly nitrosamines, are thought to be involved in the genesis of esophageal squamous cell carcinoma. Therefore, knowledge about the expression of enzymes is capable of activating nitrosamines in esophageal mucosa and precancerous lesions. Recently an interesting report described CYP2A6/2A7 and CYP2E1 can activate nitrosamines in human esophagus [100]. Such studies using precancerous lesions in both humans and rodents will make a better understanding of the importance of true preneoplasia of esophageal squamous cell carcinoma and reduce the risk of this malignancy. Risk factors for esophageal squamous cell carcinoma have been identified. These include tobacco use, alcoholism, malnutrition, infection of human papilloma virus. However, the risk factors associated with esophageal adenocarcinoma are less well defined. Symptomatic GERD is a risk factor for esophageal adenocarcinoma because long-standing GERD is associated with BE. Dysplasia in Barrett's epithelium represents a neoplastic alteration of the columnar epithelium that may progress to invasive adenocarcinoma. Recently, an interesting hypothesis that gastric infection with H. pylori may protect the esophagus from GERD and its complications has been proposed [101]. This may suggest a relationship between the rise of esophageal adenocarcinoma and a declining prevalence of $\mathrm{H}$. pylori infection in Western countries. To confirm this hypothesis and establish the effective prevention methods, further investigations should be done using animal models producing precancerous lesions resembling those in humans.

\section{Acknowledgements}

This work was partly supported by a Grant-in-Aid for the 3rd Terms Comprehensive 10-Year Strategy for Cancer Control from the Ministry of Health, Labour and Welfare of Japan, Grants-in-Aid (No. 22790638 and No. 25460988) from the Ministry of Education, Science, Sports and Culture of Japan and a grant from Takeda Science Foundation.

\section{References}

[1] Jemal, A., Bray, F., Center, M.M., Ferlay, J., Ward, E. and Forman, D. (2011) Global Cancer Statistics. CA: A Cancer Journal for Clinicians, 61, 69-90. http://dx.doi.org/10.3322/caac.20107

[2] Pisani, P., Parkin, D.M., Bray, F. and Ferlay, J. (1999) Estimates of the Worldwide Mortality from 25 Cancers in 1990. International Journal of Cancer, 83, 18-29. http://dx.doi.org/10.1002/(SICI)1097-0215(19990924)83:1<18::AID-IJC5>3.0.CO;2-M

[3] Farrow, D.C. and Vaughan, T.L. (1996) Determinants of Survival Following the Diagnosis of Esophageal Adenocarcinoma (United States). Cancer Causes Control, 7, 322-327. http://dx.doi.org/10.1007/BF00052937

[4] Matsuda, A., Matsuda, T., Shibata, A., Katanoda, K., Sobue, T. and Nishimoto, H. (2013) Cancer Incidence and Incidence Rates in Japan in 2007: A Study of 21 Population-Based Cancer Registries for the Monitoring of Cancer Incidence in Japan (MCIJ) Project. Japanese Journal of Clinical Oncology, 43, 328-336. http://dx.doi.org/10.1093/jico/hys233

[5] Enzinger, P.C. and Mayer, R.J. (2003) Esophageal Cancer. The New England Journal of Medicine, 349, $2241-2252$. http://dx.doi.org/10.1056/NEJMra035010

[6] Munoz, N. and Day, N.E. (1996) Esophageal Cancer. In: Schottenfeld, D. and Fraumeni, J.E.J., Eds., Cancer Epidemiology and Prevention, Oxford University Press, New York, 681-706.

[7] Blot, W.J. (1994) Esophageal Cancer Trends and Risk Factors. Seminars in Oncology, 21, 403-410.

[8] Craddock, V.M. (1992) Aetiology of Oesophageal Cancer: Some Operative Factors. European Journal of Cancer Prevention, 1, 89-103. http://dx.doi.org/10.1097/00008469-199202000-00002

[9] Gao, Y.T., McLaughlin, J.K., Blot, W.J., Ji, B.T., Dai, Q. and Fraumeni Jr., J.F. (1994) Reduced Risk of Esophageal Cancer Associated with Green Tea Consumption. Journal of the National Cancer Institute, 86, 855-858. http://dx.doi.org/10.1093/jnci/86.11.855 
[10] Tanaka, T. (1997) Chemoprevention of Human Cancer: Biology and Therapy. Critical Reviews in Oncology/Hematology, 25, 139-174. http://dx.doi.org/10.1016/S1040-8428(97)00232-1

[11] Tanaka, T., Makita, H., Kawabata, K., Mori, H., Kakumoto, M., Satoh, K., Hara, A., Sumida, T., Fukutani, K. and Ogawa, H. (1997) Modulation of N-Methyl-N-Amylnitrosamine-Induced Rat Oesophageal Tumourigenesis by Dietary Feeding of Diosmin and Hesperidin, Both Alone and in Combination. Carcinogenesis, 18, 761-769. http://dx.doi.org/10.1093/carcin/18.4.761

[12] Chu, F.S. and Li, G.Y. (1994) Simultaneous Occurrence of Fumonisin B1 and Other Mycotoxins in Moldy Corn Collected from the People's Republic of China in Regions with High Incidences of Esophageal Cancer. Applied and Environmental Microbiology, 60, 847-852.

[13] Devesa, S.S., Blot, W.J. and Fraumeni Jr., J.F. (1998) Changing Patterns in the Incidence of Esophageal and Gastric Carcinoma in the United States. Cancer, 83, 2049-2053. http://dx.doi.org/10.1002/(SICI)1097-0142(19981115)83:10<2049::AID-CNCR1>3.0.CO;2-2

[14] Parkin, D.M., Whelan, S.L., Ferlay, J., Raymond, L. and Young, J. (1997) Cancer Incidence in Five Continents. IARC Scientific Publications, Lyon, 1-1240.

[15] Blot, W.J., Devesa, S.S., Kneller, R.W. and Fraumeni Jr., J.F. (1991) Rising Incidence of Adenocarcinoma of the Esophagus and Gastric Cardia. JAMA, 265, 1287-1289. http://dx.doi.org/10.1001/jama.1991.03460100089030

[16] Brown, L.M., Silverman, D.T., Pottern, L.M., Schoenberg, J.B., Greenberg, R.S., Swanson, G.M., Liff, J.M., Schwartz, A.G., Hayes, R.B., Blot, W.J. and Hoover, R.N. (1994) Adenocarcinoma of the Esophagus and Esophagogastric Junction in White Men in the United States: Alcohol, Tobacco, and Socioeconomic Factors. Cancer Causes \& Control, 5, 333-340. http://dx.doi.org/10.1007/BF01804984

[17] Lippman, S.M. and Hong, W.K. (1989) Second Malignant Tumors in Head and Neck Squamous Cell Carcinoma: The Overshadowing Threat for Patients with Early-Stage Disease. International Journal of Radiation Oncology*Biology* Physics, 17, 691-694. http://dx.doi.org/10.1016/0360-3016(89)90126-0

[18] Slaughter, D.P., Southwick, H.W. and Smejkal, W. (1953) Field Cancerization in Oral Stratified Squamous Epithelium; Clinical Implications of Multicentric Origin. Cancer, 6, 963-968. http://dx.doi.org/10.1002/1097-0142(195309)6:5<963::AID-CNCR2820060515>3.0.CO;2-Q

[19] Thomson, P.J. (2002) Field Change and Oral Cancer: New Evidence for Widespread Carcinogenesis? International Journal of Oral and Maxillofacial Surgery, 31, 262-266. http://dx.doi.org/10.1054/ijom.2002.0220

[20] Lightdale, C.J. (1999) Esophageal Cancer. American College of Gastroenterology. The American Journal of Gastroenterology, 94, 20-29. http://dx.doi.org/10.1111/j.1572-0241.1999.00767.x

[21] Sugimachi, K., Sumiyoshi, K., Nozoe, T., Yasuda, M., Watanabe, M., Kitamura, K., Tsutsui, S., Mori, M. and Kuwano, H. (1995) Carcinogenesis and Histogenesis of Esophageal Carcinoma. Cancer, 75, 1440-1445. http://dx.doi.org/10.1002/1097-0142(19950315)75:6+<1440::AID-CNCR2820751508>3.0.CO;2-9

[22] Hameeteman, W., Tytgat, G.N., Houthoff, H.J. and van den Tweel, J.G. (1989) Barrett’s Esophagus: Development of Dysplasia and Adenocarcinoma. Gastroenterology, 96, 1249-1256.

[23] Miros, M., Kerlin, P. and Walker, N. (1991) Only Patients with Dysplasia Progress to Adenocarcinoma in Barrett's Oesophagus. Gut, 32, 1441-1446. http://dx.doi.org/10.1136/gut.32.12.1441

[24] Haggitt, R.C. (1994) Barrett’s Esophagus, Dysplasia, and Adenocarcinoma. Human Pathology, 25, 982-993. http://dx.doi.org/10.1016/0046-8177(94)90057-4

[25] Mosca, S., Manes, G., Monaco, R., Bellomo, P.F., Bottino, V. and Balzano, A. (2001) Squamous Papilloma of the Esophagus: Long-Term Follow Up. Journal of Gastroenterology and Hepatology, 16, 857-861. http://dx.doi.org/10.1046/j.1440-1746.2001.02531.x

[26] Ide, H., Nakamura, T., Hayashi, K., Endo, T., Kobayashi, A., Eguchi, R. and Hanyu, F. (1994) Esophageal Squamous Cell Carcinoma: Pathology and Prognosis. World Journal of Surgery, 18, 321-330. http://dx.doi.org/10.1007/BF00316810

[27] Kuwano, H., Ohno, S., Matsuda, H., Mori, M. and Sugimachi, K. (1988) Serial Histologic Evaluation of Multiple Primary Squamous Cell Carcinomas of the Esophagus. Cancer, 61, 1635-1638. http://dx.doi.org/10.1002/1097-0142(19880415)61:8<1635::AID-CNCR2820610822>3.0.CO;2-U

[28] Schmidt, L.W., Dean, P.J. and Wilson, R.T. (1986) Superficially Invasive Squamous Cell Carcinoma of the Esophagus. A Study of Seven Cases in Memphis, Tennessee. Gastroenterology, 91, 1456-1461.

[29] Lee, R.G. (1986) Adenomas Arising in Barrett’s Esophagus. American Journal of Clinical Pathology, 85, 629-632.

[30] McDonald, G.B., Brand, D.L. and Thorning, D.R. (1977) Multiple Adenomatous Neoplasms Arising in Columnarlined (Barrett's) Esophagus. Gastroenterology, 72, 1317-1321.

[31] Paraf, F., Flejou, J.F., Pignon, J.P., Fekete, F. and Potet, F. (1995) Surgical Pathology of Adenocarcinoma Arising in 
Barrett’s Esophagus. Analysis of 67 Cases. The American Journal of Surgical Pathology, 19, 183-191. http://dx.doi.org/10.1097/00000478-199502000-00007

[32] Falk, G.W. (2009) Risk Factors for Esophageal Cancer Development. Surgical Oncology Clinics of North America, 18, 469-485. http://dx.doi.org/10.1016/j.soc.2009.03.005

[33] Tanaka, H. (2014) Advances in Cancer Epidemiology in Japan. International Journal of Cancer, 134, 747-754. http://dx.doi.org/10.1002/ijc.28519

[34] Bartsch, H., Ohshima, H., Pignatelli, B. and Calmels, S. (1992) Endogenously Formed N-Nitroso Compounds and Nitrosating Agents in Human Cancer Etiology. Pharmacogenetics, 2, 272-277. http://dx.doi.org/10.1097/00008571-199212000-00005

[35] Roshandel, G., Semnani, S., Malekzadeh, R. and Dawsey, S.M. (2012) Polycyclic Aromatic Hydrocarbons and Esophageal Squamous Cell Carcinoma. Archives of Iranian Medicine, 15, 713-722.

[36] Oze, I., Matsuo, K., Ito, H., Wakai, K., Nagata, C., Mizoue, T., Tanaka, K., Tsuji, I., Tamakoshi, A., Sasazuki, S., Inoue, M. and Tsugane, S. (2012) Cigarette Smoking and Esophageal Cancer Risk: An Evaluation Based on a Systematic Review of Epidemiologic Evidence among the Japanese Population. Japanese Journal of Clinical Oncology, 42, 63-73. http://dx.doi.org/10.1093/jjco/hyr170

[37] Abdel-Latif, M.M., Duggan, S., Reynolds, J.V. and Kelleher, D. (2009) Inflammation and Esophageal Carcinogenesis. Current Opinion in Pharmacology, 9, 396-404. http://dx.doi.org/10.1016/j.coph.2009.06.010

[38] Kavanagh, M.E., O’Sullivan, K.E., O’Hanlon, C., O’Sullivan, J.N., Lysaght, J. and Reynolds, J.V. (2014) The Esophagitis to Adenocarcinoma Sequence; the Role of Inflammation. Cancer Letters, 345, 182-189. http://dx.doi.org/10.1016/j.canlet.2013.08.017

[39] Oze, I., Matsuo, K., Wakai, K., Nagata, C., Mizoue, T., Tanaka, K., Tsuji, I., Sasazuki, S., Inoue, M. and Tsugane, S. (2011) Alcohol Drinking and Esophageal Cancer Risk: An Evaluation Based on a Systematic Review of Epidemiologic Evidence among the Japanese Population. Japanese Journal of Clinical Oncology, 41, 677-692. http://dx.doi.org/10.1093/jico/hyr026

[40] Chung, C.S., Lee, Y.C., Wang, C.P., Ko, J.Y., Wang, W.L., Wu, M.S. and Wang, H.P. (2010) Secondary Prevention of Esophageal Squamous Cell Carcinoma in Areas Where Smoking, Alcohol, and Betel Quid Chewing Are Prevalent. Journal of the Formosan Medical Association, 109, 408-421. http://dx.doi.org/10.1016/S0929-6646(10)60072-1

[41] Erkal, H.S., Mendenhall, W.M., Amdur, R.J., Villaret, D.B. and Stringer, S.P. (2001) Synchronous and Metachronous Squamous Cell Carcinomas of the Head and Neck Mucosal Sites. Journal of Clinical Oncology, 19, 1358-1362.

[42] Toh, Y., Oki, E., Ohgaki, K., Sakamoto, Y., Ito, S., Egashira, A., Saeki, H., Kakeji, Y., Morita, M., Sakaguchi, Y., Okamura, T. and Maehara, Y. (2010) Alcohol Drinking, Cigarette Smoking, and the Development of Squamous Cell Carcinoma of the Esophagus: Molecular Mechanisms of Carcinogenesis. International Journal of Clinical Oncology, 15, 135-144. http://dx.doi.org/10.1007/s10147-010-0057-6

[43] Sandler, R.S., Nyren, O., Ekbom, A., Eisen, G.M., Yuen, J. and Josefsson, S. (1995) The Risk of Esophageal Cancer in Patients with Achalasia. A Population-Based Study. JAMA, 274, 1359-1362. http://dx.doi.org/10.1001/jama.1995.03530170039029

[44] Avisar, E. and Luketich, J.D. (2000) Adenocarcinoma in a Mid-Esophageal Diverticulum. The Annals of Thoracic Surgery, 69, 288-289. http://dx.doi.org/10.1016/S0003-4975(99)01201-1

[45] Islami, F., Boffetta, P., Ren, J.S., Pedoeim, L., Khatib, D. and Kamangar, F. (2009) High-Temperature Beverages and Foods and Esophageal Cancer Risk-A Systematic Review. International Journal of Cancer, 125, 491-524. http://dx.doi.org/10.1002/ijc.24445

[46] Spechler, S.J. (2013) Barrett Esophagus and Risk of Esophageal Cancer: A Clinical Review. JAMA, 310, 627-636. http://dx.doi.org/10.1001/jama.2013.226450

[47] Farrow, D.C., Vaughan, T.L., Sweeney, C., Gammon, M.D., Chow, W.H., Risch, H.A., Stanford, J.L., Hansten, P.D., Mayne, S.T., Schoenberg, J.B., Rotterdam, H., Ahsan, H., West, A.B., Dubrow, R., Fraumeni Jr., J.F. and Blot, W.J. (2000) Gastroesophageal Reflux Disease, Use of H2 Receptor Antagonists, and Risk of Esophageal and Gastric Cancer. Cancer Causes \& Control, 11, 231-238. http://dx.doi.org/10.1023/A:1008913828105

[48] Shaheen, N. and Ransohoff, D.F. (2002) Gastroesophageal Reflux, Barrett Esophagus, and Esophageal Cancer: Scientific Review. JAMA, 287, 1972-1981. http://dx.doi.org/10.1001/jama.287.15.1972

[49] Lagergren, J., Bergstrom, R., Adami, H.O. and Nyren, O. (2000) Association between Medications That Relax the Lower Esophageal Sphincter and Risk for Esophageal Adenocarcinoma. Annals of Internal Medicine, 133, 165-175. http://dx.doi.org/10.7326/0003-4819-133-3-200008010-00007

[50] O’Connor, A. and O’Morain, C. (2013) Helicobacter Pylori Infection in Europe: Current Perspectives. Expert Review of Gastroenterology Hepatology, 7, 541-548. http://dx.doi.org/10.1586/17474124.2013.824707 
[51] Rokkas, T., Pistiolas, D., Sechopoulos, P., Robotis, I. and Margantinis, G. (2007) Relationship between Helicobacter Pylori Infection and Esophageal Neoplasia: A Meta-Analysis. Clin Gastroenterol Hepatol, 5, 1413-1417, 1417 e14111412.

[52] Thrift, A.P., Pandeya, N. and Whiteman, D.C. (2012) Current Status and Future Perspectives on the Etiology of Esophageal Adenocarcinoma. Frontiers in Oncology, 2, 11.

[53] Melhado, R.E., Alderson, D. and Tucker, O. (2010) The Changing Face of Esophageal Cancer. Cancers (Basel), 2, 1379-1404. http://dx.doi.org/10.3390/cancers2031379

[54] Wolin, K.Y., Carson, K. and Colditz, G.A. (2010) Obesity and Cancer. Oncologist, 15, 556-565. http://dx.doi.org/10.1634/theoncologist.2009-0285

[55] Romero, Y., Cameron, A.J., Schaid, D.J., McDonnell, S.K., Burgart, L.J., Hardtke, C.L., Murray, J.A., Locke 3rd, G.R. (2002) Barrett's Esophagus: Prevalence in Symptomatic Relatives. The American Journal of Gastroenterology, 97, 1127-1132. http://dx.doi.org/10.1111/j.1572-0241.2002.05665.x

[56] Gerson, L.B., Shetler, K. and Triadafilopoulos, G. (2002) Prevalence of Barrett's Esophagus in Asymptomatic Individuals. Gastroenterology, 123, 461-467. http://dx.doi.org/10.1053/gast.2002.34748

[57] Wu, A.H., Wan, P. and Bernstein, L. (2001) A Multiethnic Population-Based Study of Smoking, Alcohol and Body Size and Risk of Adenocarcinomas of the Stomach and Esophagus (United States). Cancer Causes \& Control, 12, 721-732. http://dx.doi.org/10.1023/A:1011290704728

[58] Chak, A., Ochs-Balcom, H., Falk, G., Grady, W.M., Kinnard, M., Willis, J.E., Elston, R. and Eng, C. (2006) Familiality in Barrett's Esophagus, Adenocarcinoma of the Esophagus, and Adenocarcinoma of the Gastroesophageal Junction. Cancer Epidemiology, Biomarkers Prevention, 15, 1668-1673. http://dx.doi.org/10.1158/1055-9965.EPI-06-0293

[59] Varis, A., Puolakkainen, P., Savolainen, H., Kokkola, A., Salo, J., Nieminen, O., Nordling, S. and Knuutila, S. (2001) DNA Copy Number Profiling in Esophageal Barrett Adenocarcinoma: Comparison with Gastric Adenocarcinoma and Esophageal Squamous Cell Carcinoma. Cancer Genetics and Cytogenetics, 127, 53-58. http://dx.doi.org/10.1016/S0165-4608(00)00423-4

[60] Walch, A.K., Zitzelsberger, H.F., Bruch, J., Keller, G., Angermeier, D., Aubele, M.M., Mueller, J., Stein, H., Braselmann, H., Siewert, J.R., Hofler, H. and Werner, M. (2000) Chromosomal Imbalances in Barrett's Adenocarcinoma and the Metaplasia-Dysplasia-Carcinoma Sequence. The American Journal of Pathology, 156, 555-566. http://dx.doi.org/10.1016/S0002-9440(10)64760-8

[61] Wijnhoven, B.P., Tilanus, H.W. and Dinjens, W.N. (2001) Molecular Biology of Barrett’s Adenocarcinoma. Annals of Surgery, 233, 322-337. http://dx.doi.org/10.1097/00000658-200103000-00005

[62] D’Amico, T.A. (2006) Molecular Biologic Staging of Esophageal Cancer. Thoracic Surgery Clinics, 16, 317-327. http://dx.doi.org/10.1016/j.thorsurg.2006.09.001

[63] Kwong, K.F. (2005) Molecular Biology of Esophageal Cancer in the Genomics Era. Surgical Clinics of North America, 85, 539-553. http://dx.doi.org/10.1016/j.suc.2005.01.004

[64] Buxbaum, J.L. and Eloubeidi, M.A. (2009) Endoscopic Evaluation and Treatment of Esophageal Cancer. Minerva Gastroenterologica e Dietologica, 55, 455-469.

[65] Koike, T., Nakagawa, K., Iijima, K. and Shimosegawa, T. (2013) Endoscopic Resection (Endoscopic Submucosal Dissection/ Endoscopic Mucosal Resection) for Superficial Barrett’s Esophageal Cancer. Digestive Endoscopy, 25, 20-28.

[66] Pennathur, A., Farkas, A., Krasinskas, A.M., Ferson, P.F., Gooding, W.E., Gibson, M.K., Schuchert, M.J., Landreneau, R.J. and Luketich, J.D. (2009) Esophagectomy for T1 Esophageal Cancer: Outcomes in 100 Patients and Implications for Endoscopic Therapy. The Annals of Thoracic Surgery, 87, 1048-1054 (Discussion 1054-1045).

[67] Sgourakis, G., Gockel, I. and Lang, H. (2013) Endoscopic and Surgical Resection of T1a/T1b Esophageal Neoplasms: a Systematic Review. World Journal of Gastroenterology, 19, 1424-1437. http://dx.doi.org/10.3748/wjg.v19.i9.1424

[68] DiGiovanni, J. (1991) Modification of Multistage Skin Carcinogenesis in Mice. In: Ito, N. and Sugano, H., Eds., Modification of Tumor Development in Rodents, Karger, Basel, 192-229.

[69] Druckrey, H. (1972) Organospecific Carcinogenesis in the Digestive Tract. In: Nakahara, W., Takayama, S., Sugimura, T. and Odashima, S., Eds., Topics in Chemical Carcinogenesis, University Park Press, Baltimore, 73-84.

[70] Hodgson, R.M., Schweinsberg, F., Wiessler, M. and Kleihues, P. (1982) Mechanism of Esophageal Tumor Induction in Rats by N-Nitrosomethylbenzylamine and Its Ring-Methylated Analog N-Nitrosomethyl(4-Methylbenzyl)Amine. Cancer Research, 42, 2836-2840.

[71] Lijinsky, W., Saavedra, J.E., Reuber, M.D. and Singer, S.S. (1982) Esophageal Carcinogenesis in F344 Rats by Nitrosomethylethylamines Substituted in the ethyl Group. Journal of the National Cancer Institute, 68, 681-684.

[72] Siglin, J.C., Khare, L. and Stoner, G.D. (1995) Evaluation of Dose and Treatment Duration on the Esophageal Tumorigenicity of N-Nitrosomethylbenzylamine in Rats. Carcinogenesis, 16, 259-265. 
http://dx.doi.org/10.1093/carcin/16.2.259

[73] Wargovich, M.J., Woods, C., Eng, V.W., Stephens, L.C. and Gray, K. (1988) Chemoprevention of N-Nitrosomethylbenzylamine-Induced Esophageal Cancer in Rats by the Naturally Occurring Thioether, Diallyl Sulfide. Cancer Research, 48, 6872-6875.

[74] Kleihues, P., Veit, C., Wiessler, M. and Hodgson, R.M. (1981) DNA Methylation by N-Nitrosomethylbenzylamine in Target and non-target tissues of NMRI Mice. Carcinogenesis, 2, 897-899. http://dx.doi.org/10.1093/carcin/2.9.897

[75] Yamada, Y., Weller, R.O., Kleihues, P. and Ludeke, B.I. (1992) Effects of Ethanol and Various Alcoholic Beverages on the Formation of $\mathrm{O}^{6}$-Methyldeoxyguanosine from Concurrently Administered N-Nitrosomethylbenzylamine in Rats: A Dose-Response Study. Carcinogenesis, 13, 1171-1175. http://dx.doi.org/10.1093/carcin/13.7.1171

[76] Barch, D.H., Kuemmerle, S.C., Hollenberg, P.F. and Iannaccone, P.M. (1984) Esophageal Microsomal Metabolism of N-Nitrosomethylbenzylamine in the Zinc-Deficient Rat. Cancer Research, 44, 5629-5633.

[77] Mehta, R., Labuc, G.E., Urbanski, S.J. and Archer, M.C. (1984) Organ Specificity in the Microsomal Activation and Toxicity of N-Nitrosomethylbenzylamine in Various Species. Cancer Research, 44, 4017-4022.

[78] Dirsch, O.R., Koenigsmann, M., Ludeke, B.I., Scherer, E. and Kleihues, P. (1990) Bioactivation of N-Nitrosomethylbenzylamine and N-Nitrosomethyl-Amylamine in Oesophageal Papillomas. Carcinogenesis, 11, 1583-1586. http://dx.doi.org/10.1093/carcin/11.9.1583

[79] Castonguay, A., Stoner, G.D., Schut, H.A. and Hecht, S.S. (1983) Metabolism of Tobacco-Specific N-Nitrosamines by Cultured Human Tissues. Proceedings of the National Academy of Sciences of the United States of America, 80, 66946697. http://dx.doi.org/10.1073/pnas.80.21.6694

[80] Huang, Q., Stoner, G., Resau, J., Nickols, J. and Mirvish, S.S. (1992) Metabolism of N-Nitrosomethyl-n-Amylamine by Microsomes from Human and Rat Esophagus. Cancer Research, 52, 3547-3551.

[81] Stoner, G.D. and Gupta, A. (2001) Etiology and Chemoprevention of Esophageal Squamous Cell Carcinoma. Carcinogenesis, 22, 1737-1746. http://dx.doi.org/10.1093/carcin/22.11.1737

[82] Wang, Y., You, M., Reynolds, S.H., Stoner, G.D. and Anderson, M.W. (1990) Mutational Activation of the Cellular Harvey Ras Oncogene in Rat Esophageal Papillomas Induced by Methylbenzylnitrosamine. Cancer Research, 50, 15911595.

[83] Lozano, J.C., Nakazawa, H., Cros, M.P., Cabral, R. and Yamasaki, H. (1994) G--> A mutations in p53 and Ha-Ras Genes in Esophageal Papillomas Induced by N-Nitrosomethylbenzylamine in Two Strains of Rats. Molecular Carcinogenesis, 9, 33-39.

[84] Asamoto, M., Toriyama-Baba, H., Ohnishi, T., Naito, A., Ota, T., Ando, A., Ochiya, T. and Tsuda, H. (2002) Transgenic rats Carrying Human c-Ha-ras Proto-Oncogene Are Highly Susceptible to N-Nitrosomethylbenzylamine Induction of Esophageal Tumorigenesis. Japanese Journal of Cancer Research, 93, 744-751. http://dx.doi.org/10.1111/j.1349-7006.2002.tb01315.x

[85] Takahashi, M. and Imaida, K. (1991) Modification of Tumor Development in the Gastrointestinal Tract. In: Ito, N. and Sugano, H., Eds., Modification of Tumor Development in Rodents, Karger, Basel, 58-75.

[86] Mirvish, S.S. (1997) Studies on Experimental Animals Involving Surgical Procedures and/or Nitrosamine Treatment Related to the Etiology of Esophageal Adenocarcinoma. Cancer Letters, 117, 161-174. http://dx.doi.org/10.1016/S0304-3835(97)00228-0

[87] Miwa, K., Segawa, M., Takano, Y., Matsumoto, H., Sahara, H., Yagi, M., Miyazaki, I. and Hattori, T. (1994) Induction of Oesophageal and Forestomach Carcinomas in Rats by Reflux of Duodenal Contents. British Journal of Cancer, 70, 185-189. http://dx.doi.org/10.1038/bjc.1994.277

[88] Mirvish, S.S., Huang, Q., Chen, S.C., Birt, D.F., Clark, G.W., Hinder, R.A., Smyrk, T.C. and DeMeester, T.R. (1993) Metabolism of Carcinogenic Nitrosamines in the Rat and Human Esophagus and Induction of Esophageal Adenocarcinoma in Rats. Endoscopy, 25, 627-631. http://dx.doi.org/10.1055/s-2007-1010418

[89] Fein, M., Peters, J.H., Chandrasoma, P., Ireland, A.P., Oberg, S., Ritter, M.P., Bremner, C.G., Hagen, J.A. and DeMeester, T.R. (1998) Duodenoesophageal Reflux Induces Esophageal Adenocarcinoma without Exogenous Carcinogen. Journal of Gastrointestinal Surgery, 2, 260-268. http://dx.doi.org/10.1016/S1091-255X(98)80021-8

[90] Fein, M., Peters, J.H., Baril, N., McGarvey, M., Chandrasoma, P., Shibata, D., Laird, P.W. and Skinner, K.A. (1999) Loss of Function of Trp53, but Not Apc, Leads to the Development of Esophageal Adenocarcinoma in Mice with Jejunoesophageal Reflux. Journal of Surgical Research, 83, 48-55. http://dx.doi.org/10.1006/jsre.1998.5559

[91] Chen, X. and Yang, C.S. (2001) Esophageal Adenocarcinoma: A Review and Perspectives on the Mechanism of Carcinogenesis and Chemoprevention. Carcinogenesis, 22, 1119-1129. http://dx.doi.org/10.1093/carcin/22.8.1119

[92] Chen, X., Yang, G., Ding, W.Y., Bondoc, F., Curtis, S.K. and Yang, C.S. (1999) An Esophagogastroduodenal Anastomosis Model for Esophageal Adenocarcinogenesis in Rats and Enhancement by Iron Overload. Carcinogenesis, 20, 
1801-1808. http://dx.doi.org/10.1093/carcin/20.9.1801

[93] Melo, L.L., Kruel, C.D., Kliemann, L.M., Cavazzola, L.T., Boeno Rda, L., Silber, P.C. and Grossi, R.S. (1999) Influence of Surgically Induced Gastric and Gastroduodenal Content Reflux on Esophageal Carcinogenesis-Experimental Model in Wistar Female Rats. Diseases of the Esophagus, 12, 106-115. http://dx.doi.org/10.1046/j.1442-2050.1999.00011.X

[94] Goldstein, S.R., Yang, G.Y., Curtis, S.K., Reuhl, K.R., Liu, B.C., Mirvish, S.S., Newmark, H.L. and Yang, C.S. (1997) Development of Esophageal Metaplasia and Adenocarcinoma in a Rat Surgical Model without the Use of a Carcinogen. Carcinogenesis, 18, 2265-2270. http://dx.doi.org/10.1093/carcin/18.11.2265

[95] Pera, M., Grande, L., Gelabert, M., Figueras, X., Palacin, A., Elena, M., Cardesa, A., Tiburcio, A.F. and Trastek, V.F. (1998) Epithelial Cell Hyperproliferation after Biliopancreatic Reflux into the Esophagus of Rats. The Annals of Thoracic Surgery, 65, 779-786. http://dx.doi.org/10.1016/S0003-4975(97)01382-9

[96] Pera, M., Trastek, V.F., Carpenter, H.A., Fernandez, P.L., Cardesa, A., Mohr, U. and Pairolero, P.C. (1993) Influence of Pancreatic and Biliary Reflux on the Development of Esophageal Carcinoma. The Annals of Thoracic Surgery, 55, 1386-1392 (Discussion 1392-1383).

[97] Xu, X., LoCicero 3rd, J., Macri, E., Loda, M., Ellis Jr., F.H. (2000) Barrett’s Esophagus and Associated Adenocarcinoma in a Mouse Surgical Model. Journal of Surgical Research, 88, 120-124. http://dx.doi.org/10.1006/jsre.1999.5774

[98] Montesano, R., Hollstein, M. and Hainaut, P. (1996) Genetic Alterations in Esophageal Cancer and Their Relevance to Etiology and Pathogenesis: A Review. International Journal of Cancer, 69, 225-235. http://dx.doi.org/10.1002/(SICI)1097-0215(19960621)69:3<225::AID-IJC13>3.0.CO;2-6

[99] Schneider, P.M., Casson, A.G., Levin, B., Garewal, H.S., Hoelscher, A.H., Becker, K., Dittler, H.J., Cleary, K.R., Troster, M., Siewert, J.R. and Roth, J.A. (1996) Mutations of p53 in Barrett's Esophagus and Barrett's Cancer: A Prospective Study of Ninety-Eight Cases. The Journal of Thoracic and Cardiovascular Surgery, 111, 323-331 (Discussion 331-323).

[100] Godoy, W., Albano, R.M., Moraes, E.G., Pinho, P.R., Nunes, R.A., Saito, E.H., Higa, C., Filho, I.M., Kruel, C.D., Schirmer, C.C., Gurski, R., Lang, M.A. and Pinto, L.F. (2002) CYP2A6/2A7 and CYP2E1 Expression in Human Oesophageal Mucosa: Regional and Inter-Individual Variation in Expression and Relevance to Nitrosamine Metabolism. Carcinogenesis, 23, 611-616. http://dx.doi.org/10.1093/carcin/23.4.611

[101] O’Connor, H.J. (1999) Review Article: Helicobacter Pylori and Gastro-Oesophageal Reflux Disease-Clinical Implications and Management. Alimentary Pharmacology Therapeutics, 13, 117-127. http://dx.doi.org/10.1046/j.1365-2036.1999.00460.x 
Scientific Research Publishing (SCIRP) is one of the largest Open Access journal publishers. It is currently publishing more than 200 open access, online, peer-reviewed journals covering a wide range of academic disciplines. SCIRP serves the worldwide academic communities and contributes to the progress and application of science with its publication.

Other selected journals from SCIRP are listed as below. Submit your manuscript to us via either submit@scirp.org or Online Submission Portal.
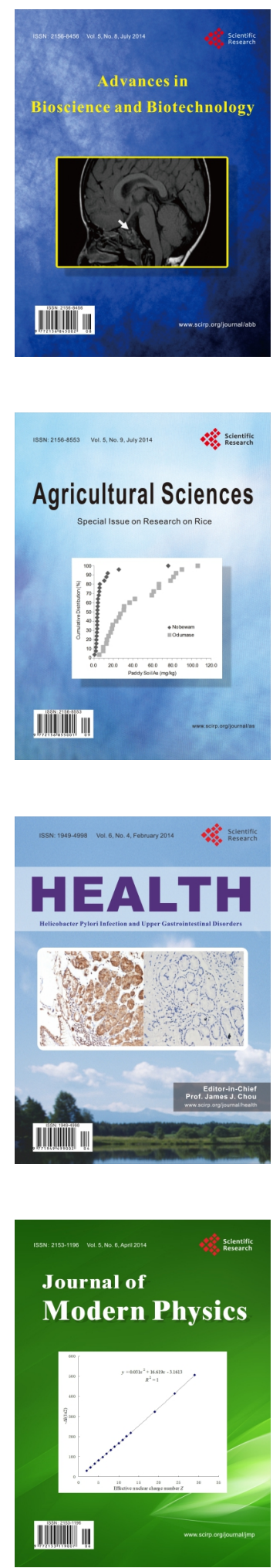
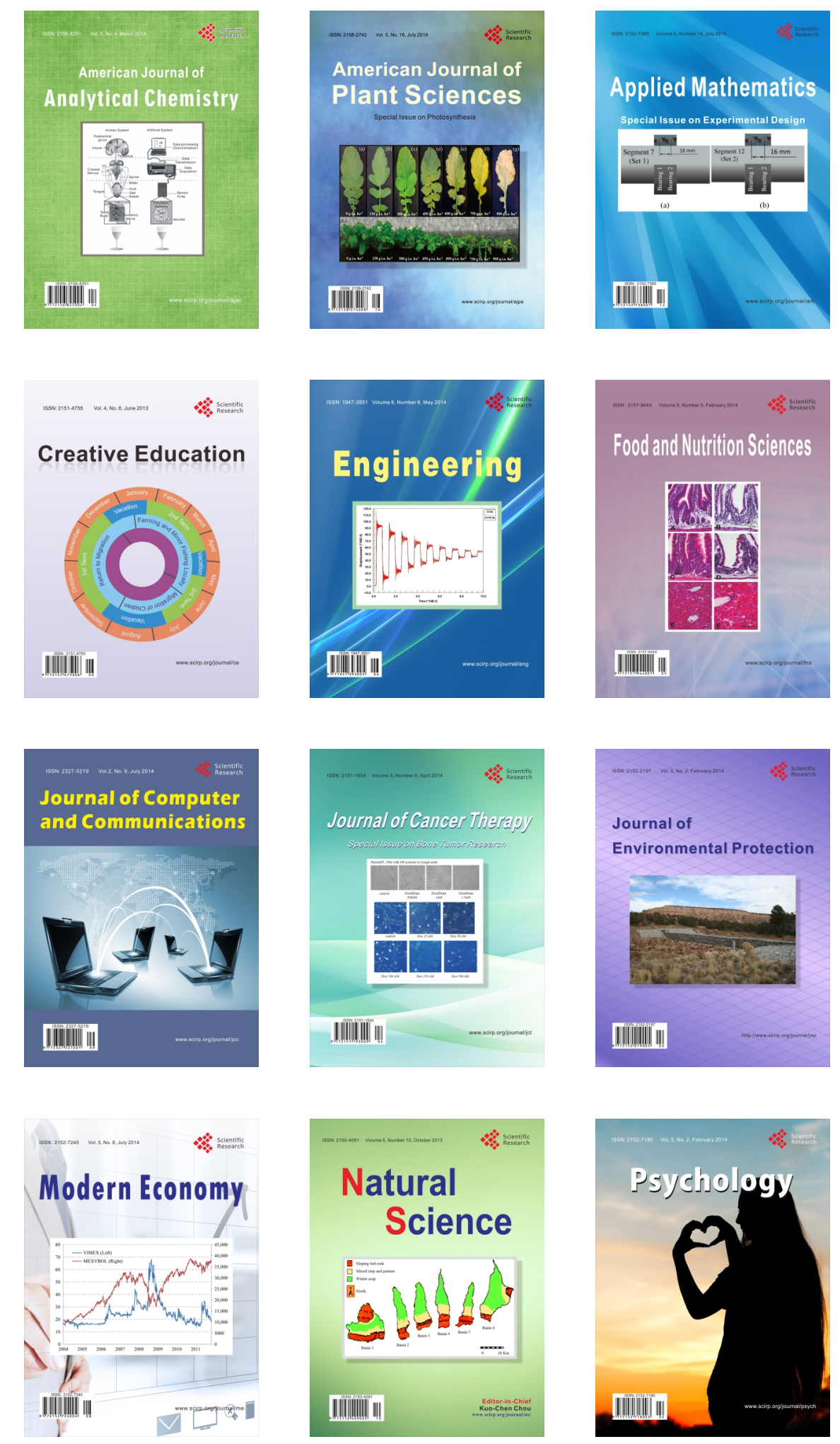